\title{
Review Article \\ Crosstalk between Endoplasmic Reticulum Stress and Protein Misfolding in Neurodegenerative Diseases
}

\author{
Cláudia M. F. Pereira \\ Center for Neuroscience and Cell Biology (CNC) and Faculty of Medicine, University of Coimbra, Largo Marquês de Pombal, \\ 3004-517 Coimbra, Portugal
}

Correspondence should be addressed to Cláudia M. F. Pereira; claudia.mf.pereira@gmail.com

Received 17 April 2013; Accepted 8 May 2013

Academic Editors: D. Arnoult, A. Colanzi, A. Hergovich, and E. Meacci

Copyright (C) 2013 Cláudia M. F. Pereira. This is an open access article distributed under the Creative Commons Attribution License, which permits unrestricted use, distribution, and reproduction in any medium, provided the original work is properly cited.

Under physiological conditions, the endoplasmic reticulum (ER) is a central subcellular compartment for protein quality control in the secretory pathway that prevents protein misfolding and aggregation. Instrumental in protein quality control in the ER is the unfolded protein response (UPR), which is activated upon ER stress to reestablish homeostasis through a sophisticated transcriptionally and translationally regulated signaling network. However, this response can lead to apoptosis if the stress cannot be alleviated. The presence of abnormal protein aggregates containing specific misfolded proteins is recognized as the basis of numerous human conformational disorders, including neurodegenerative diseases. Here, I will highlight the overwhelming evidence that the presence of specific aberrant proteins in Alzheimer's disease (AD), Parkinson's disease (PD), Huntington's disease (HD), prion diseases, and Amyotrophic Lateral Sclerosis (ALS) is intimately associated with perturbations in the ER protein quality control machinery that become incompetent to restore protein homeostasis and shift adaptive programs toward the induction of apoptotic signaling to eliminate irreversibly damaged neurons. Increasing our understanding about the deadly crosstalk between ER dysfunction and protein misfolding in these neurodegenerative diseases may stimulate the development of novel therapeutic strategies able to support neuronal survival and ameliorate disease progression.

\section{Endoplasmic Reticulum (ER) Stress and the Unfolded Protein Response (UPR)}

The endoplasmic reticulum (ER) is a crucial organelle involved in many functions in the cell, such as folding, assembly, and quality control of secretory and membrane proteins, disulfide bond formation, glycosylation, lipid biosynthesis, and $\mathrm{Ca}^{2+}$ storage and signaling [1]. When the protein-folding capacity in the ER is overwhelmed, unfolded or misfolded proteins accumulate in the ER lumen leading to ER stress [2]. To relieve stress and reestablish homeostasis, the ER activates intracellular signal transduction pathways, collectively termed the unfolded protein response (UPR), which reduces the influx of newly synthesized proteins into the ER through general translational arrest, induces the transcriptional upregulation of genes that enhance the ER proteinfolding capacity and quality control, and also degrades proteins with aberrant conformation through the proteasome (ER-associated degradation, ERAD) and lysosome-mediated autophagy [3-6]. The canonical mammalian UPR pathway involves three specialized ER stress-sensing proteins, the protein kinase R-like endoplasmic reticulum kinase (PERK), the inositol-requiring enzyme $1 \alpha$ (IRE1 $\alpha$ ), and the activating transcription factor 6 (ATF6) [7]. In cells undergoing ER stress, the ER chaperone glucose-regulated protein 78 (GRP78) dissociates from the ER transmembrane sensors [8] and promotes their activation, inducing phosphorylation and oligomerization of IREl $\alpha$ and PERK, and translocation of ATF6 to the Golgi where it is cleaved by Site 1 and Site 2 proteases (S1P and S2P) [7]. Active IREl $\alpha$ processes the mRNA encoding X-box-binding protein 1 (XBP1), a transcription factor that upregulates genes that encode mediators of ERAD, organelle biogenesis, and protein quality control [9]. PERK activation reduces protein load in the ER by decreasing general protein synthesis through phosphorylation of the $\alpha$ subunit of eukaryotic translation-initiation factor $2 \alpha$ (eIF $2 \alpha)$ which paradoxically increases selective translation of activating transcription factor 4 (ATF4) mRNA [10]. The ATF4 
protein is a member of the bZIP family of transcription factors that activates the expression of several UPR target genes involved in antioxidant responses, such as the transcription factor Nrf2, apoptosis, and autophagy [11, 12]. In ER stressed cells, ATF6 is cleaved at the Golgi apparatus, and the released cytosolic domain translocates to the nucleus where it increases the expression of ER chaperones, ERAD-related genes, and proteins involved in organelle biogenesis [13].

The levels of ER stress will influence the outcome of the cellular response [14], as depicted in Figure 1. When ER stress is mild, the cell can recover and/or adapt (Figure 1(a)). However, when ER stress is prolonged or too severe, these mechanisms fail to restore proteostasis leading to autophagy $[15,16]$ and, if the stress cannot be alleviated, to apoptosis [17] (Figure 1(b)).

\section{The ER as Central Player in Cell Survival and Death}

The ER is the main intracellular $\mathrm{Ca}^{2+}$ reservoir in mammalian cells due to the concerted action of $\mathrm{Ca}^{2+}$ pumps that allow active $\mathrm{Ca}^{2+}$ uptake, $\mathrm{Ca}^{2+}$-binding proteins that allow the storage of significant amounts of $\mathrm{Ca}^{2+}$ in ER lumen, and $\mathrm{Ca}^{2+}$ channels that allow a controlled release of $\mathrm{Ca}^{2+}$ into the cytosol in response to well-known stimuli $[18,19]$. As shown in Figure 2, ER directly communicates with mitochondria through close contacts referred to as mitochondriaassociated membranes (MAM), which are microdomains where the $\mathrm{Ca}^{2+}$ concentration is distinct from that of the bulk cytosol and that allows an efficient transfer of $\mathrm{Ca}^{2+}$ from the ER to the mitochondria, maintaining cellular metabolism and survival [20-26]. In addition, the ER-mitochondria contact site is important in the autophagosome formation [27]. The molecular bridges that regulate the contacts between both organelles include the ER inositol 1,4,5-trisphosphate receptor $\left(\mathrm{IP}_{3} \mathrm{R}\right)$ and the voltage-dependent anion channels (VDAC) located in the outer mitochondrial membrane, which are physically coupled through the cytosolic chaperone glucose-regulated protein $75 \mathrm{kDa}$ (GRP75). $\mathrm{IP}_{3} \mathrm{Rs}$, together with ryanodine receptors (RyR), accounts for the formation of microdomains of high $\mathrm{Ca}^{2+}$ concentration that are needed to activate the transport of the ion into the mitochondrial matrix through the mitochondrial calcium uniporter (MCU) [28]. In addition, the dynamin-related GTPase mitofusin 2 (Mfn2) on the ER forms homo-heterodimers with Mfn1 or Mfn2 on mitochondria to keep the tight contacts between the two organelles [29]. Moreover, PACS-2 (mainly localized at the ER) and dynamin-related GTPase protein 1 (Drp1) indirectly control the distance between the two organelles through regulation of mitochondrial morphology and distribution (Figures 1 and 2). MAM-located $\mathrm{IP}_{3}$ Rs seem to be essential for a constitutive $\mathrm{Ca}^{2+}$ release from the ER to mitochondria to support mitochondrial bioenergetics [30]. The amount of $\mathrm{Ca}^{2+}$ released through the $\mathrm{IP}_{3} \mathrm{R}$ that can be transmitted to mitochondria can be controlled by the ER chaperone Sigma-1 receptor (Sig-1R) that is able to sense $\mathrm{Ca}^{2+}$ concentrations in the ER [31]. In accordance, expression of a novel splice variant of Sig-1R was recently shown to interfere with mitochondrial energy production, promoting cellular apoptosis [32].

Recently, intracellular $\mathrm{Ca}^{2+}$ signaling and $\mathrm{IP}_{3} \mathrm{Rs}$ have been implicated in autophagy [33]. Knockdown or chemical inhibition of $\mathrm{IP}_{3}$ Rs resulted in stimulation of autophagy [34]. Furthermore, Beclin 1 was shown to interact with the $\mathrm{IP}_{3} \mathrm{R}$ [35] promoting $\mathrm{Ca}^{2+}$ signaling through $\mathrm{IP}_{3} \mathrm{Rs}$, finally leading to autophagy [36]. The ER membrane protein Bax inhibitor1 (BI-1) was also shown to promote autophagy in an $\mathrm{IP}_{3} \mathrm{R}-$ dependent manner by reducing steady-state levels of ER $\mathrm{Ca}^{2+}$ via $\mathrm{IP}_{3} \mathrm{Rs}$, influencing mitochondrial bioenergetics, reducing oxygen consumption, impacting cellular ATP levels, and stimulating autophagy [37].

Disruption of contact sites and impairment of $\mathrm{Ca}^{2+}$ coupling between ER and mitochondria have profound consequences for cellular function and in extreme cases lead to apoptosis [38] (Figure 2). It is thus crucial to avoid either a too low or a too high level of ER-to-mitochondria $\mathrm{Ca}^{2+}$ transfer. An increase in the distance between the two compartments inhibits $\mathrm{Ca}^{2+}$ flux to the mitochondrial matrix, compromising $\mathrm{Ca}^{2+}$-dependent regulation of mitochondrial metabolism and ATP production, finally leading to cell death, and, on the other hand, decreasing the space between both organelles promotes mitochondrial $\mathrm{Ca}^{2+}$ overload that can lead to changes in the permeability of the outer mitochondrial membrane, release of proapoptotic factors like cytochrome $\mathrm{c}$, ultimately leading to apoptosome formation, caspase activation, and apoptosis induction [39]. During the adaptive phase of ER stress, an early increase in cellular bioenergetics and mitochondrial metabolism was shown to occur, but during the cell death response, ER stress was found to exert profound deleterious effects on mitochondrial function and to activate an apoptotic pathway, which depends upon $\mathrm{Ca}^{2+}$ transfer from the ER to the mitochondria [40,41]. The MAM has been implicated in this deadly transfer since its disruption, achieved by small interference RNA (siRNA) knockdown of PACS-2, resulted in the inhibition of ER $\mathrm{Ca}^{2+}$ release and apoptosis onset [42]. Finally, ER folding chaperones such as calnexin and calreticulin and oxidoreductases such as ERp44, ERp57, and $\mathrm{ERO} 1 \alpha$ regulate $\mathrm{Ca}^{2+}$ flux from the ER through interaction with $\mathrm{IP}_{3} \mathrm{Rs}$, which is affected during apoptosis progression, suggesting that the extent of MAM targeting of ER chaperones and oxidoreductases could shift the readout of ER-mitochondria $\mathrm{Ca}^{2+}$ exchange from housekeeping to apoptotic [43].

In the event of chronic or unmitigated ER stress, the UPR activates apoptotic cascades [44-46]. The release of $\mathrm{Ca}^{2+}$ from the ER involves the cleavage of the ER membraneassociated caspase-12, which subsequently initiates a cascade of caspase proteolysis that promotes apoptosis [47-49]. Signaling through the PERK branch of the UPR also promotes apoptosis. ATF4 induces the expression of the transcription factor $\mathrm{C} / \mathrm{EBP}$-homologous protein $(\mathrm{CHOP})$ that inhibits the expression of antiapoptotic $\mathrm{Bcl}_{2}$ family proteins and activates the transcription of proapoptotic $\mathrm{Bcl}_{2}$ family members, activating two ER-localized $\mathrm{Bcl}_{2}$ family members, Bak and Bax [50], that relocalize to mitochondria and lead to the release of proapoptotic signals such as cytochrome $\mathrm{c}$ and caspase 


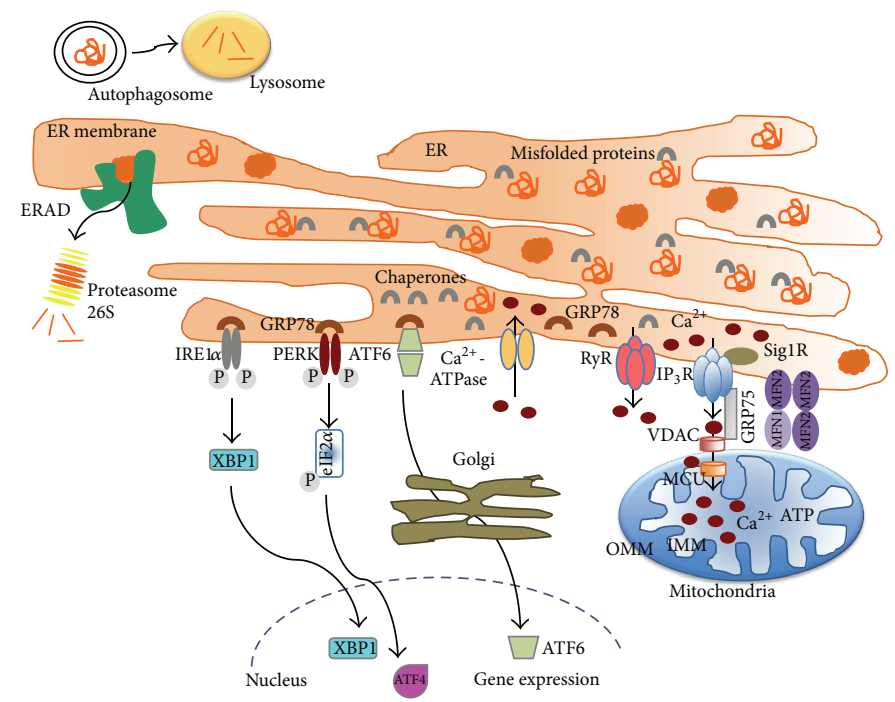

(a)

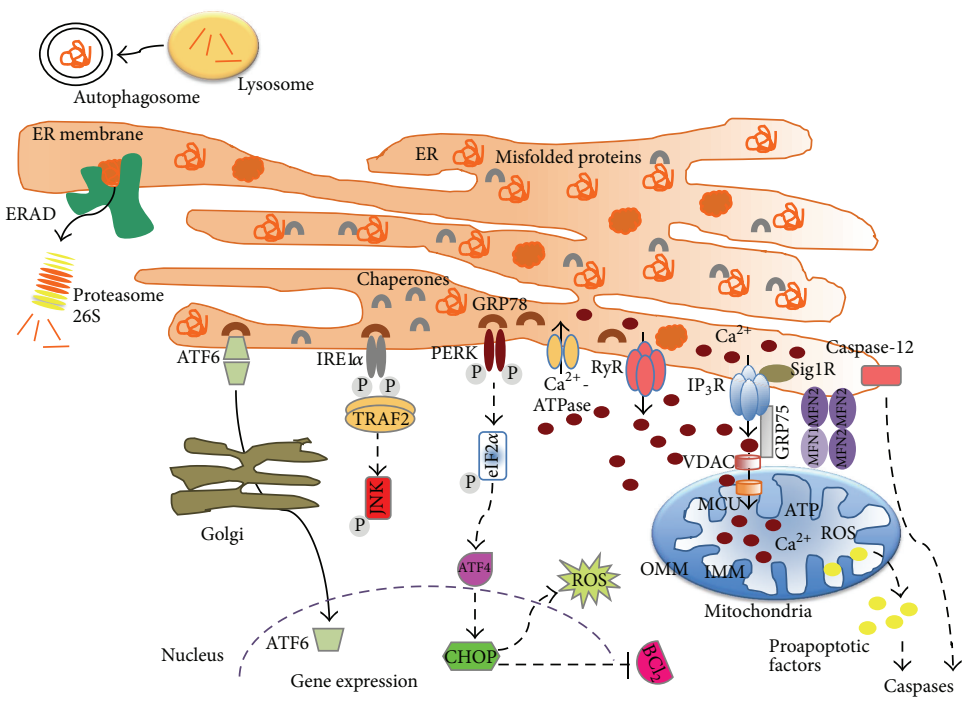

(b)

FIGURE 1: Adaptive signaling of the UPR and ER stress-mediated apoptotic pathways. (a) In unstressed cells, the three UPR transducers, ATF6, IRE1 $\alpha$, and PERK, are associated with the ER chaperone GRP78. Upon accumulation of misfolded proteins in the ER lumen, these sensors are released and activated: ATF6 translocates to the Golgi where it is cleaved, the cytosolic fragment of ATF6 migrates to the nucleus, and IRE1 $\alpha$ and PERK are oligomerized and autophosphorylated. Phosphorylated IRE1 $\alpha$ catalyzes the splicing of XBP1 mRNA, and activated PERK phosphorylates eIF $2 \alpha$, which attenuates the general translation rate while inducing the translation of selective mRNAs such as ATF4. These downstream effectors of the UPR branches induce the expression of the genes encoding proteins that function to augment the ER proteinfolding capacity. Simultaneously, ERAD is accelerated to remove terminally misfolded proteins through degradation in the proteasome, and aggregated proteins are degraded through the autophagic lysosomal pathway. ER-to-mitochondria $\mathrm{Ca}^{2+}$ transfer maintains mitochondrial metabolism and ATP production and preserves cell survival. (b) Under conditions of prolonged or severe ER stress, the sensors ATF6, IRE1 $\alpha$, and PERK also initiate apoptotic signaling cascades. $\mathrm{ER} \mathrm{Ca}^{2+}$ efflux through the RyRs and $\mathrm{IP}_{3} \mathrm{Rs}$ induces mitochondrial Ca ${ }^{2+}$ overload, ROS accumulation, and ATP depletion and thus activates the mitochondria-dependent apoptosis. CHOP, one of the PERK downstream effectors, inhibits the expression of Bcl-2 and triggers ROS generation, thus promoting apoptosis. Activated IRE1 $\alpha$ recruits TRAF2, which leads to the activation of JNK and also activates the ER-resident caspase-12 leading to activation of the caspase cascade.

activation. CHOP increases and activates the transcription of GADD34, which interacts with protein phosphatase I to catalyze eIF2 $\alpha$ dephosphorylation [51,52]. Dephosphorylated eIF2 $\alpha$ in turn increases protein synthesis and oxidation leading to ER protein overload [53]. CHOP also triggers
$\mathrm{Ca}^{2+}$-dependent apoptosis through an ERO1 $\alpha$-IP ${ }_{3} \mathrm{R}$ pathway on MAM. In ER-stressed cells, ERO1 $\alpha$, which can be localized on MAM [54], was shown to be induced by CHOP, and siRNA knockdown of ERO1 $\alpha$ suppressed apoptosis [55]. In addition, the same study demonstrated that $\mathrm{IP}_{3}$-induced $\mathrm{Ca}^{2+}$ 


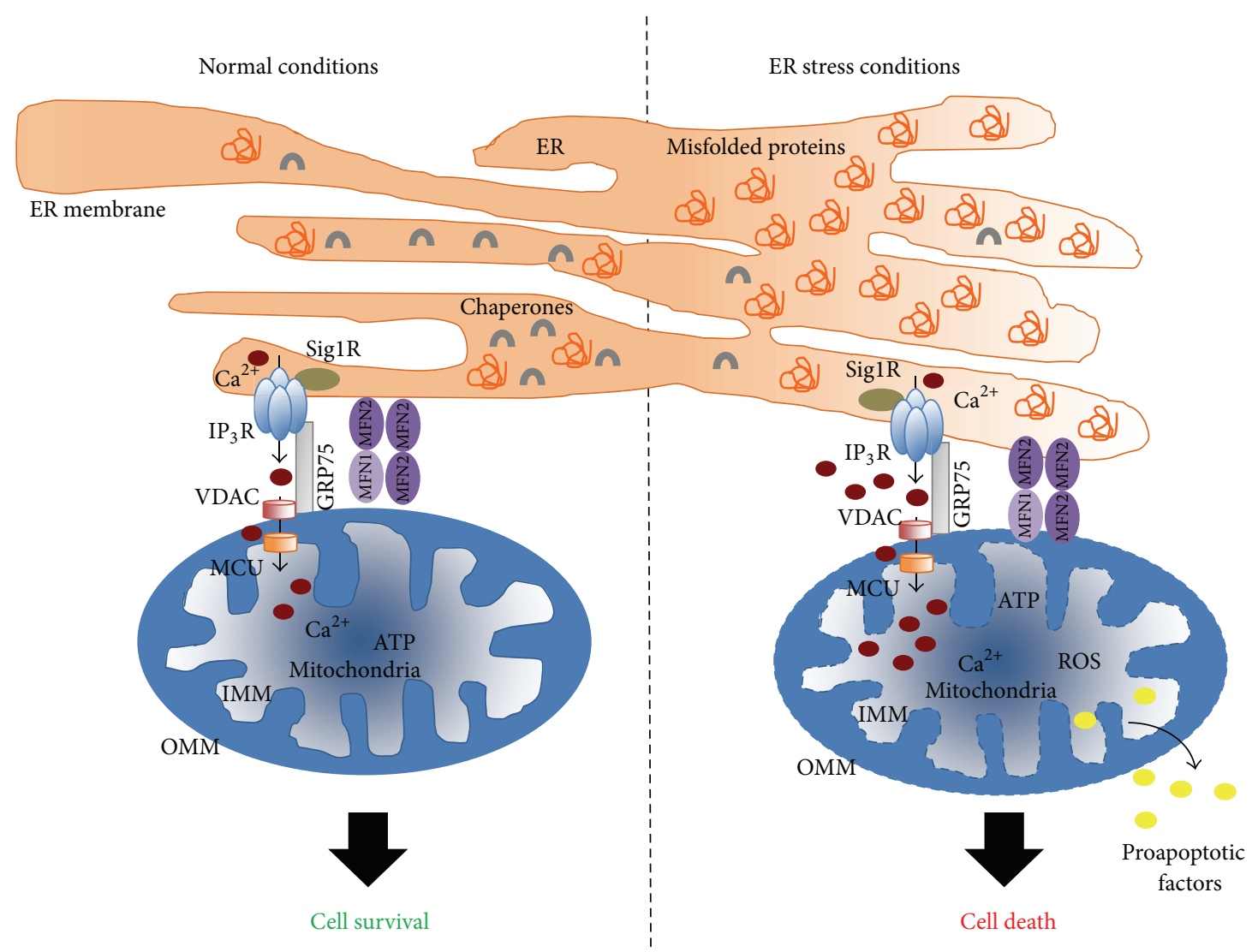

FIGURE 2: $\mathrm{Ca}^{2+}$ transfer between the ER and mitochondria under normal and ER stress conditions. Direct $\mathrm{Ca}^{2+}$ transfer from the ER lumen into the mitochondria occurs at contact sites that are maintained by Mfn2 on the ER and Mfn1 or Mfn2 on mitochondria and is facilitated by the $\mathrm{IP}_{3} \mathrm{R} / \mathrm{GRP} 75 / \mathrm{VDAC}$ complex that also involves the mitochondrial calcium uniporter (MCU) on the outer mitochondrial membrane (IMM). The amount of $\mathrm{Ca}^{2+}$ released through the $\mathrm{IP}_{3} \mathrm{R}$ that can be transmitted to mitochondria, which can be controlled by the ER chaperone Sig1R, determines cell fate. In normal conditions $\mathrm{Ca}^{2+}$ released from the ER to mitochondria triggers cellular metabolism and ATP production. However, mitochondrial $\mathrm{Ca}^{2+}$ overload induced by ER stress sensitizes mitochondria to generate ROS and to release apoptotic factors.

release increased during ER stress and was blocked by siRNAmediated silencing of ERO1 $\alpha$ or $\mathrm{IP}_{3} \mathrm{R}$. Signaling through the IRE1 $\alpha$ branch of the UPR can induce apoptosis under ER stress conditions due to the association of IREl $\alpha$ with TNFreceptor-associated factor 2 (TRAF2), cleaving caspase-12, and apoptosis-signal-regulating kinase (ASK1) [49], which in turn enhances the proapoptotic activity of $\mathrm{Bcl}_{2}$ family members through c-Jun $\mathrm{N}$-terminal kinase (JNK) signaling [56]. Numerous pieces of evidence demonstrate that several members of the $\mathrm{Bcl}_{2}$ family, such as $\mathrm{Bcl}_{2}$ itself, $\mathrm{Bax}$, and Bak, naturally localize to both mitochondria and the ER and modulate $\mathrm{Ca}^{2+}$ content in both organelles, controlling the amount of ER-releasable $\mathrm{Ca}^{2+}$ that can reach mitochondria [57]. Furthermore, diminished $\mathrm{Ca}^{2+}$ flux from the ER to the mitochondria upon phosphorylation of $\mathrm{IP}_{3} \mathrm{R}$ by Akt was demonstrated to reduce cellular sensitivity to apoptotic stimuli [58]. Cytochrome c released from mitochondria can also bind to $\mathrm{ER} \mathrm{IP}_{3} \mathrm{R}$ and promotes $\mathrm{Ca}^{2+}$ release through this channel that triggers the extrusion of a large amount of cytochrome $\mathrm{c}$ from all the mitochondria in the cell, amplifying the death signal [59]. It has been reported that ER $\mathrm{Ca}^{2+}$ release conditions can trigger mitochondrial fission and cristae remodelling, facilitating cytochrome $\mathrm{c}$ release and subsequent apoptosis [60,61], but division of mitochondrial network can also block $\mathrm{Ca}^{2+}$-mediated apoptosis [62]. Apoptosis associated with chronic ER stress may contribute to pathophysiological processes involved in a number of prevalent diseases, including neurodegenerative diseases [49, 63].

\section{ER Stress in Protein Misfolding Neurodegenerative Diseases}

Neurodegenerative disorders represent a class of diseases that are generally fatal and incurable. The abnormal accumulation in susceptible brain regions of specific misfolded proteins in intracellular inclusions or extracellular aggregates has been recognized to be crucial in the pathogenesis of various neurodegenerative diseases, including Alzheimer's disease (AD), Parkinson's disease (PD), Amyotrophic Lateral Sclerosis (ALS), polyglutamine (polyQ) diseases such as Huntington's disease (HD), and transmissible spongiform encephalopathies (TSE) or prion diseases (Table 1). Consequently, these neurodegenerative diseases are generally considered conformational disorders, and increasing evidence 
TABLE 1: Clinical and pathological features of neurodegenerative diseases.

\begin{tabular}{|c|c|c|c|c|}
\hline Disease & Main clinical features & $\begin{array}{l}\text { Affected brain } \\
\text { region }\end{array}$ & Protein & $\begin{array}{c}\text { Localization of } \\
\text { aggregates/inclusions }\end{array}$ \\
\hline \multirow{2}{*}{ Alzheimer's disease (AD) } & \multirow{2}{*}{ Progressive dementia } & Hippocampus & $\mathrm{A} \beta$ & Extracellular \\
\hline & & Cerebral cortex & Tau & Cytoplasmatic \\
\hline Parkinson's disease (AD) & Movement disorder & Substantia nigra & $\alpha$ Syn & Cytoplasmatic \\
\hline $\begin{array}{l}\text { Amyotrophic Lateral } \\
\text { Sclerosis (ALS) }\end{array}$ & Movement disorder & $\begin{array}{l}\text { Motor cortex } \\
\text { Brainstem }\end{array}$ & $\begin{array}{l}\text { SOD1 } \\
\text { FUS } \\
\text { TDP-43 } \\
\text { VAPB }\end{array}$ & Cytoplasmatic \\
\hline Huntington's disease (HD) & $\begin{array}{l}\text { Motor and psychiatric } \\
\text { problems, dementia }\end{array}$ & $\begin{array}{c}\text { Striatum } \\
\text { Cerebral cortex }\end{array}$ & HTT & $\begin{array}{c}\text { Cytoplasmatic } \\
\text { Nuclear }\end{array}$ \\
\hline $\begin{array}{l}\text { Transmissible spongiform } \\
\text { encephalopathies (TSE) }\end{array}$ & $\begin{array}{l}\text { Dementia, ataxia, } \\
\text { psychiatric problems, } \\
\text { or insomnia }\end{array}$ & Various regions & Prion & Extracellular \\
\hline
\end{tabular}

A $\beta$ : amyloid- $\beta$; $\alpha$ Syn: $\alpha$-synuclein; HTT: huntingtin; SOD1: $\mathrm{Cu}$, Zn-superoxide dismutase; FUS: fused in sarcoma; TDP-43: transactive response DNA-binding protein-43;VAPB: vesicle-associated membrane protein-associated protein $B$.

suggests that genetic mutations and/or environmental factors can be the instigators of protein misfolding and aggregation [64]. Numerous studies implicate that the impairment of the protein quality control mechanisms may lead to the abnormal accumulation of disease-specific proteins, and, conversely, several proteins that are known to be associate with neurodegenerative diseases have been identified as important regulators of protein quality control systems [65-67]. The pieces of evidence for an association between these protein misfolding disorders and impaired protein quality control in the secretory pathway, in particular in the ER, are now beginning to emerge, and deregulation of the UPR or the occurrence of chronic ER stress has been proposed to contribute to the pathological process [68-76]. Markers of ER stress-induced UPR activation have been found in postmortem samples from affected patients as well as in animal models of AD, PD, ALS, HD, and TSE [77-88]. Furthermore, pharmacological approaches and genetic manipulation in cellular and animal models of these disorders have provided promising results concerning the contribution of ER stress to the neurodegenerative process $[17,89]$, suggesting that strategies to target and modulate the UPR signaling pathways and $\mathrm{ER} \mathrm{Ca}^{2+}$ homeostasis during ER stress could have therapeutic benefits for intervention in several neurodegenerative diseases with different etiologies.

\section{Interplay between ER Stress and Disease-Associated Misfolded Proteins}

4.1. Amyloid- $\beta$ Peptide. Alzheimer's disease (AD) is the most common neurodegenerative disorder, clinically characterized by progressive cognitive impairment. The pathologic hallmarks in the AD brain, which are identical in both familial and sporadic cases, include synaptic and neuronal loss in the hippocampus and cerebral cortex, deposition of neurofibrillary tangles composed of hyperphosphorylated tau, and the abnormal accumulation of the amyloid- $\beta(\mathrm{A} \beta)$ peptide in senile plaques. Recent observations suggest that chronic ER stress is a fundamental pathological event in $\mathrm{AD}$, and several
ER stress markers were found in postmortem samples from affected patients $[75,83]$.

Numerous pieces of evidence support that $\mathrm{A} \beta$ is a key trigger in the pathogenesis of $\mathrm{AD}$, and $\mathrm{ER}$ stress has been implicated as a mediator of $\mathrm{A} \beta$ production, secretion, and neurotoxicity [90]. ER stress-related genes are differentially regulated during the initial and intermediate stages of $\mathrm{A} \beta$ deposition in the hippocampus and cortex of rat brain supporting a close link between ER stress and A $\beta$ accumulation in early AD [91]. Presenilin-1 (PS1) was shown to be upregulated by an ATF4-dependent process under ER stress conditions, increasing $\gamma$-secretase activity and $\mathrm{A} \beta$ secretion, which was suppressed by modified UPR signalling with quercetin [92]. Furthermore, based on results obtained in the neuronal cell line $\mathrm{CAD}$, it was proposed that an oligomerization-prone pool of $\mathrm{A} \beta$ is generated within the ER lumen as a result of deficits in kinesin-1-dependent axonal transport through a mechanism that involves JNK-mediated amyloid precursor protein (APP) phosphorylation and cleavage by the amyloidogenic pathway [93]. In HEK293 and COS-7 cells, the E693Delta mutant APP promoted accumulation of $\mathrm{A} \beta$ oligomers within the ER, concomitantly with a strong induction of the ER stress markers GRP78 and phosphorylated eIF2 $\alpha$, activation of caspase- 4 (human homologous of caspase-12) and caspase-3, and as DNA fragmentation, suggesting that mutant APP induces alteration of $\mathrm{A} \beta$ trafficking and subsequent ER stress-induced apoptosis via enhancement of its intracellular oligomerization [94]. It was also found that in transgenic mice expressing APP $(\mathrm{E} 693 \Delta)$ intraneuronal $\mathrm{A} \beta$ oligomers accumulate in the ER in hippocampal neurons and cause cell death by inducing ER stress [95]. In this study, accumulation of $\mathrm{A} \beta$ oligomers in the ER was detected concomitantly with upregulation of GRP78 and HRD1 (an ERAD E3 ubiquitin ligase) in the hippocampi of 18-month-old mice. The studies by Kaneko and coauthors suggest that the breakdown of HRD1-mediated ERAD causes $A \beta$ generation and ER stress. HRD1 was shown to promote APP ubiquitination and degradation, resulting in decreased generation of $\mathrm{A} \beta$. On the other hand, 
suppression of HRD1 expression induced APP accumulation that increased production of $\mathrm{A} \beta$ associated with ER stress. In addition, ATF6- and XBP1-induced upregulation of ERAD triggered APP degradation and reduced $\mathrm{A} \beta$ production [96].

Several pieces of evidence demonstrated that $\mathrm{A} \beta$ is able to trigger an ER stress response leading to synaptic and neuronal loss. In vitro studies demonstrated that $\mathrm{A} \beta$ increases the levels of markers of the ER stress response [97-100]. In 2000, Nakagawa and colleagues [101] showed that caspase-12deficient cortical neurons were defective in apoptosis induced by A $\beta$. Similarly, human caspase- 4 , a member of caspase- 1 subfamily that includes caspase-12, was found to be localized to the ER membrane and to be cleaved in cells treated with ER stress-inducing reagents and by administration of $\mathrm{A} \beta$, and $\mathrm{A} \beta$-induced apoptosis was reduced by siRNAs to caspase4 , supporting that caspase-4 can function as an ER stressspecific caspase in humans and may be involved in pathogenesis of $\mathrm{AD}$ [102]. It was further found in cultured cortical neurons that $\mathrm{A} \beta$ stabilizes and activates caspase- 12 protein by inhibiting proteasome activity through the increase in the expression of E2-25K/Hip-2, an E2 ubiquitin-conjugating enzyme [103]. The same study further demonstrated that E2$25 \mathrm{~K} / \mathrm{Hip}-2$ is an essential upstream regulator of $\mathrm{A} \beta$-induced cell death triggered by ER stress-activated caspase- 12 . In PC12 neuronal cells, soluble $\mathrm{A} \beta$ exposure triggered caspase-12mediated apoptosis that was shown to be associated with secretion of the ER chaperone GRP94 [104]. The involvement of caspase- 12 activation in $\mathrm{A} \beta$-induced synaptic toxicity was also demonstrated in cortical and hippocampal synaptosomes isolated from 3xTg-AD mice [105]. Recently, it was found that accumulation of $A \beta$ with a toxic turn at positions 22 and 23 was promoted in mutant PS1-transfected cells, concomitantly with increased levels of the ER stress marker GRP78, and further enhanced by cotransfection of cells with the APP gene [106]. Furthermore, this study showed that toxic turn $A \beta$ and GRP78 were detected in the neurons of young $3 \times \mathrm{Tg}-\mathrm{AD}$ mice that were cognitively unimpaired while high-molecular weight $\mathrm{A} \beta$ oligomers were detected in the neurons of older mice with apparent memory dysfunction. Previously, Lai and colleagues [107] have found that soluble low-molecular weight $\mathrm{A} \beta$ disrupted the anchoring between ER and microtubules (MT), leading to collapse of ER, decreased stability of MT, autophagy, and enhanced lysosomal degradation, which were partially inhibited by paclitaxel (Taxol), an MT-stabilizing agent. Pretreatment of neurons with the MT-stabilizing drugs paclitaxel and epothilone A was shown to prevent the initiation of $\mathrm{A} \beta$ - and thapsigargininduced UPR and blocked cell death and the cytoskeletal disorganization induced by these insults, suggesting that loss of cytoskeletal integrity is a very early step in the response to a variety of toxic stimuli and that preservation of MT stability might be important in preventing ER dysfunction and subsequent cell death induced by $\mathrm{A} \beta$ in neurons [108]. Evidence obtained in cultured hippocampal neurons supports that interaction of $\mathrm{A} \beta$ oligomers with the $\mathrm{N}$-methyl-D-aspartate receptor (NMDAR) for glutamate, in particular with the GluN2B subunits, occurs upstream of perturbations in ER $\mathrm{Ca}^{2+}$ homeostasis and upregulation of ER stress markers [109]. A $\beta$ was also reported to induce a translational block that leads to widespread ER stress, which activates JNK3, similar to which is detected in human AD cases and familial AD mouse models. JNK3 in turn phosphorylated APP, thereby facilitating its endocytosis and subsequent processing and $\mathrm{A} \beta$ production. Concomitantly, deletion of JNK3 from familial Alzheimer's disease (FAD) mice results in a dramatic reduction in $\mathrm{A} \beta$ levels and overall plaque loads and increased neuronal number and improved cognition [110].

Perturbation of ER $\mathrm{Ca}^{2+}$ homeostasis, a trigger for the accumulation of unfolded or misfolded proteins and activation of the ER stress response, seems to play an important role in the onset or progression of neuronal dysfunction in $\mathrm{AD}$ [111]. Recent studies in AD transgenic mice have described enhanced $\mathrm{Ca}^{2+}$ responses associated with increased levels of ER RyRs and altered synaptic transmission and plasticity mechanisms before the onset of histopathology and cognitive deficits [112-116]. APP overexpression enhanced cytosolic $\mathrm{Ca}^{2+}$ levels and cell death in response to $\mathrm{ER} \mathrm{Ca}^{2+}$ depletion induced by thapsigargin in a CHOP- and store-operated channel- (SOC-) dependent manner [117]. A $\beta$ was shown to be a trigger for $\mathrm{ER} \mathrm{Ca}^{2+}$ depletion in cortical neurons through $\mathrm{IP}_{3} \mathrm{R}$ - and RyR-mediated $\mathrm{Ca}^{2+}$ channels, increasing intracellular $\mathrm{Ca}^{2+}$ levels and leading to the activation of a mitochondria-mediated apoptotic cell death pathway [118121], which was further demonstrated using mitochondrial DNA-depleted rho 0 cells exposed to toxic A $\beta$ or widely used ER stressors [122]. Nanomolar concentrations of A $\beta$ peptide were shown to increase $\mathrm{IP}_{3} \mathrm{R}$ and VDAC protein expression and to elevate the number of ER-mitochondria contact points and mitochondrial $\mathrm{Ca}^{2+}$ concentrations in neurons, suggesting an important role of ER-mitochondria contacts and crosstalk in $\mathrm{AD}$ pathology [123]. In cortical neuronal cultures, $\mathrm{A} \beta$-induced ER stress was shown to be potentiated under mitochondrial dysfunction conditions induced by chemical inhibition of complex IV of the mitochondrial respiratory chain [124], as previously demonstrated in cybrid cells harbouring the complex IV defect from $\mathrm{AD}$ patients [125]. Furthermore, $\mathrm{Ca}^{2+}$ released from the ER in A $\beta$-treated neurons was implicated in glycogen synthase kinase 3 beta(GSK3 $\beta-$ ) mediated tau phosphorylation [126]. In addition, perturbation of intracellular $\mathrm{Ca}^{2+}$ homeostasis induced in cortical neurons by extracellular $\mathrm{A} \beta$ was correlated with an increase of RyR3 expression and activity, endogenously produced $\mathrm{A} \beta$, and increased RyR3 $\mathrm{mRNA}$ and protein in cortical neurons and brain tissue from transgenic CRND8 mice, a mouse model of $\mathrm{AD}$ [127]. $\mathrm{A} \beta$ exposure was shown to be followed by an extracellular-dependent early increase in intracellular $\mathrm{Ca}^{2+}$ concentration elicited by a calpaindependent cleavage of the $\mathrm{Na}^{+} / \mathrm{Ca}^{2+}$ exchanger isoform NCX3 with enhanced activity, which was paralleled by an increased $\mathrm{Ca}^{2+}$ content in the ER stores [128]. By contrast, in the late phase of $\mathrm{A} \beta$ exposure, the NCX3 proteolytic cleavage abruptly ceased simultaneously with a reduction in $\mathrm{ER} \mathrm{Ca}{ }^{2+}$ content that triggered ER stress, as revealed by caspase- 12 activation, concomitantly with neuronal death, and these findings were further supported by the earlier $\mathrm{A} \beta$-induced caspase-12 activation and reinforced neuronal cell death in NCX3-silenced neurons. 
Recent evidence suggests that strategies able to ameliorate ER stress could prevent $A \beta$ pathology. It was demonstrated in the Tg2576 mouse model of AD that administration of 4-phenylbutyrate (PBA) reversed spatial learning and memory deficits without altering $A \beta$ burden and decreased tau phosphorylation through the increase in the inactive form of the GSK $3 \beta$. Furthermore, PBA restored brain histone acetylation levels and activated the transcription of synaptic plasticity markers [129]. Systemic administration of PBA, acting through its chemical chaperone-like activity and via the transcriptional activation of a cluster of proteins required for the induction of synaptic plasticity and structural remodeling, was shown to mitigate ER stress in Tg2576 mice which was accompanied by reversal of learning deficits, independently of the disease stage, clearance of intraneuronal $A \beta$ accumulation, and restoration of dendritic spine densities of hippocampal CA1 pyramidal neurons, concomitantly with increased levels of the NMDA receptor subunit NR2B and the synaptic scaffold SAP102 [130]. Additionally, the same authors demonstrated that chronic administration of PBA, starting before the onset of disease symptoms, prevents agerelated memory deficits in Tg2576 mice associated with a decrease in $\mathrm{A} \beta$ pathology and inflammation [131]. Findings by Wiley and colleagues demonstrating that PBA ameliorates the cognitive and pathological features of $\mathrm{AD}$ also support the investigation of PBA as a therapeutic for AD. In APPoverexpressing neuroblastoma cells, PBA blocked the repressive effects of the ER stressors tunicamycin and thapsigargin upon APP proteolysis, UPR activation and apoptosis, and, in unstressed cells, PBA stimulated $\gamma$-secretase-mediated cleavage of APP, in the absence of any significant effects upon $\mathrm{A} \beta$ production, by promoting APP trafficking through the secretory pathway and the stimulation of the nonpathogenic $\alpha / \gamma$ cleavage [132]. Furthermore, in APPswePSidelta9 AD transgenic mice treated with PBA for 14 months in the drinking water, secretase-mediated APP cleavage was increased; incidence and size of amyloid plaques throughout the cortex and hippocampus decreased and were paralleled by increased memory retention, suggesting that PBA modifies amyloid aggregation or pathogenesis [133].

Silencing CHOP gene expression with siRNA was shown to protect against $\mathrm{AD}$-like pathology triggered by 27 -hydroxycholesterol in organotypic slices from adult rabbit hippocampus, reducing $A \beta$ production, tau phosphorylation, generation of reactive oxygen species (ROS), activation of proinflammatory cytokines, and apoptosis [134]. In SK-NSH human neuroblastoma cells, $\mathrm{A} \beta$ treatment was shown to activate the protective PERK-eIF2 $\alpha$ pathway as well as UPR apoptotic pathways such as $\mathrm{CHOP}$ and caspase- 4 , and PERK knockdown enhanced $\mathrm{A} \beta$ neurotoxicity while salubrinal, an activator of the eIF2 $\alpha$ pathway, significantly attenuated apoptosis in $\mathrm{A} \beta$-treated cells, indicating that PERK-eIF $2 \alpha$ pathway is a potential target for therapeutic applications in $\mathrm{AD}$ [135]. Furthermore, the active form of the transcription factor XBP1 was shown to be neuroprotective in flies expressing $A \beta$ and mammalian cultured neurons treated with $\mathrm{A} \beta$ oligomers, which was mediated by the downregulation of a specific isoform of the $\mathrm{RyR} \mathrm{Ca}^{2+}$ channel, RyR3, preventing the accumulation of free $\mathrm{Ca}^{2+}$ in the cytosol [136]. In $\mathrm{A} \beta$-injected rats, a JNK-specific inhibitor was demonstrated to suppress $\mathrm{A} \beta$-induced ER stress concomitantly with upregulation of prosurvival mitochondrial proteins including nuclear respiratory factor-1 (NRF-1), peroxisome proliferator-activated receptor gamma coactivator 1-alpha (PGCl $\alpha$ ), and mitochondrial transcription factor A (TFAM), possibly through a Nrf2-dependent mechanism, supporting that JNK carries out partial destructive effects of $A \beta$ in rat brain [137]. Neuronal death induced by prolonged exposure of cultured cortical neurons to $\mathrm{A} \beta$ was substantially attenuated by agonists of the Sig1R [138], which demonstrated antiamnesic and neuroprotective effects against $\mathrm{A} \beta$-induced toxicity in mice [139-141], suggesting that SiglR agonists might function as neuroprotectant agents in $\mathrm{AD}$.

Taken together, these studies support that ER stress is a trigger for $\mathrm{A} \beta$ formation and that prolonged UPR activation and loss of $\mathrm{ER} \mathrm{Ca}^{2+}$ homeostasis are induced by $\mathrm{A} \beta$ oligomers in the early stages of $\mathrm{AD}$-associated cognitive decline. Therefore, therapeutic strategies targeting the ER could prevent disease progression.

4.2. Tau. Tau is a microtubule- (MT-) associated protein found mostly in neurons that plays a role in regulating MT assembly and stabilization [142, 143]. Under pathological conditions tau can become hyperphosphorylated, resulting in its dissociation from MT (loss of function) and assembly into abnormal toxic filaments (toxic gain of function) [144]. The abnormal phosphorylation and intracellular accumulation of tau protein are a feature of a group of increasingly prevalent disorders that are classified as tauopathies, including $\mathrm{AD}$. The mechanisms behind tau hyperphosphorylation in tauopathies remain largely unknown, but recent reports support that ER stress is associated with the early stages of tau pathology in these disorders $[145,146]$. In AD brains, increased levels of UPR markers were shown to closely correlate with the presence of phosphorylated tau (p-tau) and GSK-3 $\beta$ [83], suggesting that UPR activation in AD neurons occurs at an early stage of neurofibrillary degeneration and that the prolonged activation of the UPR is involved in both tau phosphorylation and neurodegeneration in $\mathrm{AD}$ pathogenesis. More recently, UPR activation was investigated in sporadic tauopathies like progressive supranuclear palsy (PSP) and Pick's disease (PiD) and familial cases with frontotemporal dementia and parkinsonism linked to chromosome 17 (FTDP-17) which carry mutations in the gene encoding for tau (MAPT). A strong association between the presence of UPR activation markers and diffuse staining of p-tau was observed in neurons and glia in frontotemporal lobar degeneration with tau pathology (FTLD-tau) cases, in contrast to FTLD subtypes negative for tau pathology or in nonneurological controls, and was also prominently present in relatively young carriers of MAPT mutation [147], demonstrating that UPR activation is intimately connected with the accumulation and aggregation of p-tau in tauopathies. Furthermore, several lines of evidence indicate that ER stressinduced UPR activation contributes to increase the levels of phosphorylated tau and vice versa. In primary cultures of rat cortical neurons treated with okadaic acid (OA), 
which blocks the dephosphorylation of proteins by protein phosphatase $2 \mathrm{~A}$ and therefore promotes tau phosphorylation, there were found increased levels of active PERK and eIF2 $\alpha$, splicing of mRNA for XBP-1, and elevated levels of GADD153 mRNA, and, on the other hand, thapsigargin stimulated phosphorylation of tau at Thr231, Ser262, and Ser396 [148]. GSK-3 $\beta$ was found to be responsible for tau hyperphosphorylation induced by ER stressors both in vivo and in vitro, and the ER chaperone GRP78 was shown to play an essential role by promoting the binding of GSK-3 $\beta$ to tau [149]. Accordingly, the GSK- $3 \beta$ inhibitor lithium chloride was demonstrated to efficiently attenuate thapsigargininduced tau hyperphosphorylation in cell cultures and rat brains [150]. The role played by tau hyperphosphorylation in ER stress-induced apoptosis was then explored in cell lines with stable expression of human tau (HEK293/tau). These cells were demonstrated to be more resistant to thapsigargininduced apoptosis in comparison with cells expressing the empty vector (HEK293/vec), and this inhibition positively correlated with the time-dependent increase of tau phosphorylation and also with PERK, eIF2 $\alpha$, and IRE1 $\alpha$ activation and increased cleavage of ATF6 and ATF4, suggesting that tau hyperphosphorylation could attenuate the ER stressinduced apoptosis through upregulation of the UPR system [151]. Recently, ER stress was shown to increase total endogenous tau protein in primary cultured neurons because its degradation through the ubiquitin-proteasome pathway becomes delayed [152]. Nijholt and colleagues [153] reported that, in brain tissue from patients with different tauopathies, lysosomal accumulations of pSer (21/9) GSK-3 are found in neurons with markers for UPR activation and demonstrated in vitro that UPR activation increases the activity of GSK-3 by a novel mechanism, the autophagy/lysosomal degradation of the inactive pSer (21/9) GSK-3. In a transgenic Drosophila model of AD and related tauopathies it was demonstrated that activation of the UPR response can ameliorate the toxicity of tau in vivo [154].

Collectively, the above findings support that ER stress is intimately related with tau phosphorylation and accumulation in several tauopathies and that ER stress inhibition can ameliorate neurodegeneration induced by tau.

4.3. $\alpha$-Synuclein. Parkinson's disease (PD) is a chronic and progressive neurodegenerative disorder characterized by the selective loss of dopaminergic neurons of the substantia nigra pars compacta and the accumulation of intracellular inclusions, designed Lewy bodies (LBs), mainly composed of misfolded $\alpha$-synuclein ( $\alpha$ Syn), a presynaptic neuronal protein. Point mutations in $\alpha$ Syn gene are associated with rare, early-onset forms of $\mathrm{PD}$, although aggregation of the wildtype (WT) protein is observed in the more common sporadic forms of the disease. How dysregulation of $\alpha$ Syn leads to neurodegeneration is, however, unclear. Recent postmortem analysis, showing that the UPR pathway is activated in nigral dopaminergic neurons bearing $\alpha$ Syn inclusions in the brain of PD patients, suggests that the activation of the UPR may be induced by the accumulation of $\alpha$ Syn [75]. This hypothesis is supported by a recent study showing that the misfolded protein sensor GRP78 was bound to $\alpha$ Syn and was increased in in vitro and in vivo models in which $\alpha$ Syn accumulation occurred in part within the ER [155]. In a rat model of PD induced by elevated levels of human $\alpha$ Syn, GRP78 overexpression diminished $\alpha$ Syn neurotoxicity by downregulating ER stress mediators and the level of apoptosis, promoted survival of nigral tyrosine hydroxylase $(\mathrm{TH})$ positive cells, and resulted in higher levels of striatal dopamine, probably due to the formation of a complex between GRP78 and $\alpha$ Syn [156]. Importantly, early modifications in the substantia nigra at premotor stages of $\mathrm{PD}$ (preclinical PD) were demonstrated to include abnormal small aggregates of $\alpha$ Syn in association with a plethora of altered molecular events including increased expression of ER stress markers [157]. The findings by Ito and colleagues suggest that the coexistence of human $\alpha$ Syn with catecholamine can enhance the ER stress-related toxicity in PD pathogenesis [158].

A causative link between impaired $\mathrm{ER} \mathrm{Ca}^{2+}$ homeostasis and chronic ER stress in the degenerative cascades induced by mutant $\alpha$ Syn was recently established. By using organelletargeted $\mathrm{Ca}^{2+}$-sensitive aequorin probes, it was demonstrated that $\alpha$ Syn positively affects $\mathrm{Ca}^{2+}$ transfer from the ER to the mitochondria, an effect correlated with an increase in the number of ER-mitochondria interactions [159]. Conversely, enhanced accumulation of $\alpha$ Syn into the cells causes the redistribution of $\alpha$ Syn to localized foci and, similar to $\alpha$ Syn siRNA silencing, reduced the ability of mitochondria to accumulate $\mathrm{Ca}^{2+}$, and stimulated autophagy that, in the long range, compromised cellular bioenergetics. ER stressmediated cell death induced by mutant $\alpha$ Syn was aggravated by knockdown of homocysteine-inducible ER stress protein (Herp), which maintains ER homeostasis by facilitating proteasome-mediated degradation of ER-resident $\mathrm{Ca}^{2+}$ release channels [160]. Accordingly, knockdown or pharmacological inhibition of $\mathrm{ER} \mathrm{Ca}^{2+}$ release channels ameliorated ER stress, suggesting that impaired homeostatic regulation of $\mathrm{Ca}^{2+}$ channels promotes activation of ER stress-associated apoptotic pathways. Interestingly, a sustained upregulation of ER stress markers and aberrant accumulation of $\mathrm{ER} \mathrm{Ca}^{2+}$ release channels were found in transgenic mutant A53T- $\alpha$ Syn mice [160]. In this animal model of $\alpha$-synucleinopathy, it was reported that disease onset is coincident with induction of ER chaperones in neurons exhibiting $\alpha$ Syn pathology [161]. Induction of ER stress was associated with increased levels of ER/microsomal $\alpha$ Syn monomers and aggregates, similar to what was observed in human PD cases. More important, treatment with the anti-ER stress compound salubrinal significantly attenuated disease manifestations in both the A53T- $\alpha$ Syn transgenic mouse model and the adenoassociated virus-transduced rat model of A53T $\alpha$ Syn-dependent dopaminergic neurodegeneration [161]. Induced expression of A53T $\alpha$ Syn in differentiated PC12 cells increased ER stress, elevated caspase-12 activity, and caused cell death, which was partially reverted by siRNA to knockdown caspase- 12 or by salubrinal, further indicating that ER stress contributes to mutant $\alpha$ Syn-induced cell death [112, 113]. Treatment of primary cultures from $\alpha$ Syn-overexpressing transgenic mice and cells that inducibly express WT human $\alpha$ Syn with salubrinal was shown to significantly decrease $\alpha$ Syn oligomers 
and ER stress markers to levels similar to those determined in noninduced or nontransgenic counterparts [162]. Recent evidence supports that $\alpha$ Syn oligomers accumulate in ER, and $\alpha$ Syn oligomer-dependent ER stress is pathologically relevant for PD and other $\alpha$-synucleinopathies. $\alpha$ Syn that accumulates within ER/microsome was shown to form toxic oligomers in mouse and human brain with the $\alpha$-synucleinopathy. In the mouse model, $\alpha$ Syn oligomers were formed before the onset of disease and continued to accumulate with the disease progression. Significantly, treatment of $\alpha$ Syn transgenic mice with salubrinal reduced ER accumulation of oligomers [163]. The protein disulfide isomerase (PDI), a stress protein abundant in ER, was found to effectively inhibit $\alpha$ Syn fibril formation in vitro and to be more avid for binding with intermediate species formed during the fibrillization process [164], providing new insight into the role of PDI in protecting ER from the deleterious effects of misfolded protein accumulation.

Evidence demonstrating that $\alpha$ Syn is a potent inducer of ER stress and ER $\mathrm{Ca}^{2+}$ dyshomeostasis leading to neuronal cell loss supports that ER might be a valid therapeutic target for PD and other synucleopathies.

4.4. Prion. Transmissible spongiform encephalopathies (TSEs), also known as prion diseases, are rare and fatal diseases that affect animals and humans and are characterized by progressive neuronal impairment as well as by the accumulation of an abnormally folded and protease resistant form of the cellular prion protein $\left(\operatorname{PrP}^{\mathrm{C}}\right)$, termed scrapie prion protein $\left(\operatorname{PrP}^{\mathrm{Sc}}\right)$. Alterations in protein folding and quality control mechanisms at the ER have been associated with the occurrence of neurodegeneration in sporadic, infectious, and familial forms of prion-related disorders [165].

A conformational change of $\operatorname{PrP}^{\mathrm{C}}$ underlies formation of $\operatorname{PrP}^{\mathrm{Sc}}$, which is closely associated with pathogenesis and transmission of prion diseases [166]. The increased protein aggregation and cellular susceptibility to ER damage induced by the expression of a dominant negative form of IRE1 $\alpha$ or XBP-1 indicate that ER stress efficiently converts $\operatorname{PrP}^{\mathrm{C}}$ into $\operatorname{PrP}^{\mathrm{Sc}}$ [167], and, in turn, $\operatorname{PrP}^{\mathrm{Sc}}$ induces neuronal apoptosis via activation of the ER stress pathway mediated by the ERresident caspase-12 [168]. Moreover, a close relationship between prion replication and induction of ER stress during different stages of the disease was demonstrated, and expression of the ER chaperone GRP58 was proposed to be an early cellular response to prion replication, acting as a neuroprotective factor against prion neurotoxicity. In a murine scrapie model, upregulation of GRP58 was detected during the presymptomatic phase and was closely followed by the formation of $\mathrm{PrP}^{\mathrm{Sc}}$ in different brain areas [169]. Accordingly, in vitro inhibition of GRP58 expression with siRNA significantly enhanced $\mathrm{PrP}^{\mathrm{Sc}}$ toxicity and, conversely, overexpression of GRP58 protected cells against $\mathrm{PrP}^{\mathrm{Sc}}$ toxicity, and decreased the rate of caspase-12 activation.

Alterations in $\mathrm{Ca}^{2+}$ homeostasis have been reported in models of both infectious and familial prion diseases [170]. A study that compared local $\mathrm{Ca}^{2+}$ movements in cerebellar granule neurons (CGN) derived from WT or PrP knockout $(\mathrm{KO})$ mice demonstrated that there was a dramatic increase of store-operated $\mathrm{Ca}^{2+}$ entry (SOCE) in PrP-KO CGN compared to WT neurons, which was rescued upon restoring $\mathrm{PrP}^{\mathrm{C}}$ expression [171]. The $\mathrm{Ca}^{2+}$ phenotype of PrP$\mathrm{KO}$ neurons was in part explained by the lower expression of the ER $\mathrm{Ca}^{2+}$-ATPases that may contribute to the lower accumulation of $\mathrm{Ca}^{2+}$ in the ER. Studies performed in neurons isolated from PrP-deficient mice implicated ER $\mathrm{Ca}^{2+}$ ATPase in the enhanced $\mathrm{Ca}^{2+}$ buffering and extrusion into the ER, which contained substantial amounts of PrP in WT neurons [172]. Taken together, these data suggest that $\operatorname{PrP}^{\mathrm{C}}$ may be involved in the control of $\mathrm{Ca}^{2+}$ homeostasis that can be deregulated due to its conversion to $\operatorname{PrP}^{\mathrm{Sc}}$. Neuro2A cells chronically infected with $\operatorname{PrP}^{\mathrm{Sc}}$ showed decreased $\mathrm{ER} \mathrm{Ca}^{2+}$ content that correlated with enhanced upregulation of UPRinducible chaperones and a higher sensitivity to ER stressinduced cell death, which were stimulated by the overexpression of the $\mathrm{Ca}^{2+}$-ATPase [173]. Furthermore, expression of PrP mutants led to accumulation of an abnormally folded and protease resistant form of the $\mathrm{PrP}^{\mathrm{C}}$ protein and partial retention at the $\mathrm{ER}$, associated with a drastic decrease of ER $\mathrm{Ca}^{2+}$ content and higher susceptibility to ER stress. In primary cultures of cortical neurons, the synthetic $\operatorname{PrP}_{106-126}$ peptide promoted the release of $\mathrm{Ca}^{2+}$ from the ER through the RyR and $\mathrm{IP}_{3} \mathrm{R}$ leading to cytosolic $\mathrm{Ca}^{2+}$ rise and accumulation of ROS, subsequently activating an apoptotic cell death pathway involving the loss of mitochondrial membrane potential, Bax translocation to mitochondria, cytochrome c release, and caspases activation $[119,120]$. The role of mitochondria in PrP-induced apoptosis was further investigated on the Ntera2 human teratocarcinoma cell line that had been depleted of their mitochondrial DNA (mtDNA), termed NT2 rho0 cells, characterized by the absence of functional mitochondria, as well as on the parental NT2 rho+ cells [174]. In this study, $\mathrm{PrP}_{106-126}$ induced ER stress in both cell lines and depleted ER $\mathrm{Ca}^{2+}$ content. In parental cells, $\operatorname{PrP}_{106-126}$ activated caspases 9 and 3, induced poly(ADP-ribose) polymerase (PARP) cleavage, and increased the number of apoptotic cells, which was prevented by inhibition of $\mathrm{ER} \mathrm{Ca}^{2+}$ releasing channels. However, in $\operatorname{PrP}_{106-126}$-treated mtDNA-depleted rho0 cells, apoptosis was not able to proceed, suggesting a deadly crosstalk between ER and mitochondria on prion diseases.

Recently, Cohen and coauthors [175] reported evidence supporting the hypothesis that Snord3A, a noncoding RNA transcript from the box C/D SnoRNA family that activates the UPR, may function as a disease marker and play an important role in the mechanism of prion disease manifestation and progression. Using global arrays, it was found that the expression of Snord3A was elevated several times in patients with Creutzfeldt Jakob disease (CJD) as compared to controls, while asymptomatic carriers presented intermediate Snord3A levels. In the brains of a mouse model mimicking CJD and in scrapie-infected mice, but not in $\operatorname{PrP}(0 / 0)$ mice, Snord3A levels were shown to be elevated in an age- and disease severity-dependent manner and were consistent with the activation of ATF6. Finally, it was shown that SnoRNAs were associated with reduced resistance to ER stress 
suggesting that Snord3A can be a potential target in CJD and other neurodegenerative conditions. The accumulation of prion protein during prion replication was shown to cause persistent translational repression of global protein synthesis by phosphorylated eIF $2 \alpha$ (p-eIF $2 \alpha$ ), associated with synaptic failure and neuronal loss in prion-diseased mice and that translational recovery in hippocampi is neuroprotective [176]. Reduction of p-eIF2 $\alpha$ levels through overexpression of the specific phosphatase GADD34, as well as reduction of levels of prion protein by siRNA, restored vital translation rates rescuing synaptic deficits and neuronal loss, thereby significantly increasing survival. In contrast, salubrinal, an inhibitor of p-eIF2 $\alpha$ dephosphorylation, exacerbated neurotoxicity and significantly reduced survival in prion-diseased mice. Based on these findings, Moreno et al. proposed that manipulation of common pathways such as translational control, rather than disease-specific approaches, may lead to new therapies preventing neuronal loss in these disorders. Accordingly, it was previously described in a brain-specific XBP1 conditional KO strain (XBP1 (Nes-/-)) infected with murine prions that the activation of stress responses, prion aggregation, neuronal loss, or animal survival triggered by prion replication were not influenced by deficiency of XBP1, a highly conserved arm of the UPR [177].

Glycosylated $\operatorname{PrP}^{\mathrm{C}}$ is found primarily at the cell surface. However, chronic ER stress and proteasomal dysfunction lead to accumulation of aggregation-prone PrP molecules in the cytosol and to neurodegeneration. Nunziante and colleagues [178] suggested a novel pathway for prion formation when protein clearance by the proteasome is impaired demonstrating in different cell lines that proteasome dysfunction and ER stress enhance trafficking of PrP protein aggregates through the secretory pathway and increase accumulation of pathologic $\operatorname{Pr} \mathrm{P}^{\mathrm{Sc}}$, which could be reversed by overexpression of proteins of the cellular quality control. Results obtained in the brains of scrapie-infected hamsters demonstrated an abnormal upregulation of PDI that started at the early stage and persistently increased till later stage and also demonstrated active S-nitrosylated modifications of PDI, both in the brains of scrapie-infected rodents and in cultured cells transiently expressing PrP mutants [179]. Moreover, the same study found that apoptosis induced by misfolded PrP proteins could be regulated by PDI.

Although $\mathrm{PrP}^{\mathrm{Sc}}$ is hypothesized to be the pathogenic agent in prion diseases, little accumulation of $\operatorname{PrP}^{\mathrm{Sc}}$ is detected in some kinds of natural and experimental prion diseases, including some special genetic forms. Some recent studies have shown that point mutations associated with familial prion diseases increase the amount of cellular ${ }^{\mathrm{Ctm}} \mathrm{PrP}$, one of the specific topology forms of PrP, that may work as the ultimate cause of neurodegeneration [180]. The retention of the ${ }^{\mathrm{Ctm}} \mathrm{PrP}$ in ER is able to induce ER stress and apoptosis, which is supported by upregulation of ER chaperones and proapoptotic transcription factors [41, 181], suggesting that mutant PrP misfolds in the early secretory pathway and resides longer in the ER stimulating ER stress-related pathogenic mechanisms. However, the role of ER stress on the neurotoxic effect of mutant PrP in genetic prion diseases is controversial.
In transgenic mice, primary neurons and transfected cells expressing two different mutant PrP, key elements of the UPR, and the activity of the ubiquitin proteasome system (UPS) were checked, and neither ER stress nor perturbation of proteasome activity was detected [182].

In conclusion, ER stress is implicated in the conversion of $\mathrm{PrP}^{\mathrm{C}}$ to neurotoxic conformations that in turn induce a sustained activation of UPR and deregulation of ER $\mathrm{Ca}^{2+}$ homeostasis, finally leading to cell death. Therefore, ER dysfunction can be a promising target for therapeutic intervention in prion diseases.

4.5. Huntingtin. Huntington's disease (HD) is an autosomal dominant neurodegenerative disorder caused by an expansion of cytosine-adenine-guanine (CAG) repeats in the huntingtin (HTT) gene that expands a polyglutamine region in the aminoterminal domain of HTT, which is characterized by progressive motor impairment, cognitive decline and neuropsychiatric disturbances. The aggregation of mutant HTT (mHTT) results in the selective degeneration of striatal medium spiny neurons and certain neuron subsets in the cortex [183].

Several recent reports indicate that cytoplasmic/nuclear located mHTT may generate chronic ER stress leading to neuronal dysfunction since it interferes with many essential processes related to the secretory pathway, including inhibition of ERAD, altered ER/Golgi vesicular trafficking and axonal transport, disrupted autophagy and abnormal ER $\mathrm{Ca}^{2+}$ homeostasis [73]. In 2007, Atwal and colleagues proposed that HTT has a normal biological function as an ER-associated protein due to the presence of an amphipathic $\alpha$ helical membrane-binding domain formed by the 18 amino-acid aminoterminus and demonstrated that loss of ER targeting in response to ER stress results in increased nuclear entry of mHTT and greatly increased toxicity in a striatalderived mouse cell line. In addition, this aminoterminal membrane association domain is capable of targeting HTT to late endosomes as well as autophagic vesicles. In response to ER stress, mHTT-expressing cells have a perturbed ER and an increase in autophagic vesicles [184]. These findings support that HTT protein regulates autophagy in response to ER stress [185]. Recently, it was shown in genetic HD mouse models that phosphorylation of two serines within the amphipathic $\alpha$ helical domain that can target HTT to the ER is important for disease development since it releases HTT from the ER to allow nuclear entry and prevent nuclear export during a transient stress response event [186].

Using cell-based aggregation assays, human full-length cDNAs were screened, and the secretory carrier membrane protein 5 (SCAMP5) was isolated as a modulator of polyQ track protein aggregation. Expression of SCAMP5 was shown to be markedly increased in the striatum of HD patients and to be induced in cultured striatal neurons by ER stress leading to the impairment of endocytosis, which in turn enhances mHTT aggregation [187]. Results obtained in neuronal cells, striatal tissues of HD mouse models, HD patients, and an HD fly model suggest that IRE1 $\alpha$ also plays an essential role in ER stress-mediated aggregation of $\mathrm{mHTT}$ via the inhibition of autophagy flux and thus neuronal toxicity of mHTT 
aggregates [188]. Furthermore, tandem affinity purification and quantitative proteomics performed in a striatal cell line revealed that expanded HTT interacts with the stress granuleassociated proteins Caprin-1 and G3BP and is redistributed to RNA stress granules under ER stress conditions [189].

Studies performed in neuronal PC6.3 cells overexpressing the aminoterminal of mHTT showed that this protein activates ER stress causing cell death and that inhibition of ER stress by salubrinal increases cell survival [190]. The extra long form of $\mathrm{Bim}$ ( $\mathrm{Bcl}_{2}$ interacting mediator of cell death), BimEL, was identified to play an essential role in mHTTinduced ER stress-mediated cell death in cell lines expressing the aminoterminus of mHTT and in a mouse model of HD [191]. Using live-cell imaging it was demonstrated that full-length mHTT expression in striatal neurons impairs misfolded secretory protein turnover as a result of ERAD dysfunction, decreases the ER stress threshold, and increases vulnerability to insults [192]. Accordingly, overexpression of GRP78 was shown to protect N2a cells against mHTT proteins, reduce formation of aggregates, inhibit caspase-12 activation, and block cell death [193]. In yeast cells and neuronlike PC12 cells expressing polyQ-expanded HTT fragments it was reported a specific, immediate, and drastic defect in ERAD that was shown to result from the entrapment of the essential ERAD proteins Npl4, Ufd1, and p97 [194]. The impact of mHTT in ERAD was further supported by the studies demonstrating that mHTT interacts and negatively interferes with the function of gp78 as an ER membraneanchored ubiquitin ligase (E3) involved in ERAD that are aggravated by polyQ expansion [195].

Zuleta and colleagues [80] delivered an active form of XBP1 locally into the striatum of adult mice and coexpressed this factor with a large fragment of $\mathrm{mHTT}$ as a fusion protein with RFP (Htt588 (Q95)-mRFP) to directly visualize the accumulation of HTT inclusions in the brain. Using this approach, a significant reduction in the accumulation of intracellular inclusions was observed when XBP1 was coexpressed in the striatum [80]. These results contrast with recent findings by Vidal and collaborators [196] indicating a protective effect of XBP1 deficiency in neurodegeneration, using XBP1-deficient mHTT transgenic mice that were shown to be more resistant to developing disease features and exhibited a drastic decrease in mHTT levels. The protective effects of XBP1 deficiency were associated with enhanced macroautophagy in both cellular and animal models of HD through an augmented expression of Forkhead box O1 (FoxO1), a key transcription factor regulating autophagy in neurons, providing strong evidence supporting an involvement of $\mathrm{XBP1}$ in HD pathogenesis due to the control of autophagy levels [196].

mHTT protein was shown to specifically bind to and activate the carboxy-terminal cytosolic region (the IC10 fragment) of the $\mathrm{IP}_{3} \mathrm{R} 1$ [197] supporting the hypothesis that deregulated neuronal $\mathrm{Ca}^{2+}$ signaling plays an important role in HD pathology. Lately, these authors utilized viral vectors to introduce GFP-IC10 fusion protein into striatal medium spiny neurons (MSNs) from yeast artificial chromosome transgenic (YAC128) HD mouse model both in vitro and in vivo and demonstrated that the IC10 fragment stabilizes neuronal $\mathrm{Ca}^{2+}$ signaling, protects YAC128 MSN from glutamate-induced apoptosis, alleviates motor deficits, and reduces neuronal pathology in YAC128 HD mice [198]. These results support an importance of $\mathrm{IP}_{3} \mathrm{R} 1-\mathrm{mHTT}$ association for $\mathrm{HD}$ pathogenesis and validate $\mathrm{IP}_{3} \mathrm{R} 1$ as a therapeutic target for HD treatment. The potential beneficial effect of dantrolene, an antagonist of the ER RyR and clinically relevant $\mathrm{Ca}^{2+}$ signaling stabilizer, was evaluated in the YAC128 HD mouse model. Pretreatment with dantrolene protected YAC128 MSN from glutamate excitotoxicity and long-term feeding dantrolene to YAC128 mice resulted in significantly improved motor performance, reduced the loss of striatal neurons, and reduced formation of HTT nuclear aggregates [199]. Recent results provide novel evidence supporting that altered RyR function is involved in neuronal cell death, and its stabilization might be beneficial for treatment of HD. Suzuki and coauthors, using intracellular $\mathrm{Ca}^{2+}$ imaging, showed that mHTT caused excessive basal $\mathrm{Ca}^{2+}$ leak through $\mathrm{RyR}$ leading to depletion of internal $\mathrm{Ca}^{2+}$ store that was also observed in striatal and cortical neurons from the R6/2 HD model mice. Moreover, expression of FK506-binding protein12 (FKBP12), a RyR stabilizer, suppressed both $\mathrm{Ca}^{2+}$ leak and cell death, and inhibitors of RyR were shown to attenuate cell death induced by mHTT, while coexpression of RyR enhanced HTT toxicity [200].

The aggregation and subcellular localization of mHTT were found to be affected under ER stress conditions. Furthermore, mHTT-induced striatal neuronal death was shown to involve UPR activation, loss of $\mathrm{ER} \mathrm{Ca}^{2+}$ homeostasis and ERAD inhibition, suggesting that modulation of ER function could be beneficial in HD.

4.6. Cu, Zn Superoxide Dismutase ( $m S O D 1)$, Fused in Sarcoma (FUS), Transactive Response DNA-Binding Protein-43 (TDP43), and Vesicle-Associated Membrane Protein-Associated Protein $B$ (VAPB). Amyotrophic Lateral Sclerosis (ALS) is an adult onset neurodegenerative disease pathologically characterized by the massive loss of motor neurons in the spinal cord, brain stem, and cerebral cortex and by the misfolding and aggregation of distinct proteins in affected tissues [201]. There is a consensus in the field that ALS is a multifactorial pathology, and, among the proposed hypothesis, ER stress has been suggested to be an important pathway to cell death in sporadic and familial ALS $[202,203]$.

Mutations in $\mathrm{Cu}, \mathrm{Zn}$ superoxide dismutase (SOD1) are causative for a subset of familial ALS cases. Mutant SOD1 was shown to accumulate inside the ER, where it forms insoluble high-molecular weight species, in an age- and region-specific manner. In transgenic mutant SOD1 mice, these alterations developed over the course of the disease and occurred in the affected spinal cord but not in the nonaffected cerebellum [204]. Using the anterior part of the lumbar spinal cord of transgenic mice carrying a mutation (G93A) in SOD1 gene, it was found that the levels of active phosphorylated PERK and eIF $2 \alpha$ were increased at the presymptomatic age while the expression of activated caspase- 12 was increased at both the presymptomatic and the late symptomatic ages, strongly 
suggesting that the balance between anti- and proapoptotic proteins related to ER stress is impaired from the presymptomatic stage in this ALS mouse model [205].

Oh and colleagues [206] demonstrated that the ALSrelated G85R SOD1 and G93A SOD1 mutants, which formed visible aggregates and induced cell death when overexpressed in Neuro2a cells, caused signs of both early and late ER stress responses, namely, PERK and IRE $\alpha$ phosphorylation, JNK activation, ATF6 translocation, XBP1 mRNA splicing, and caspase-12 activation, possibly prior to the formation of visible aggregates. Importantly, the ER stress inhibitor salubrinal delayed the formation of insoluble aggregates of the mutant SOD1 and suppressed cell death, and, in turn, overexpression of ER-targeted Bcl-xL protected the cells from the mutant SOD1-induced cytotoxicity [206]. Accordingly, studies performed in NSC34 cells and in an animal model of ALS provided direct evidence of activated UPR, increased $\mathrm{XBP1}$, ATF6 mRNA, and protein levels and phosphorylation of eIF $2 \alpha$, in motor neurons which overexpress human pathogenic mutant SOD1 but not in wild-type motor neurons [207]. In addition, upregulation of UPR was shown to occur prior to the onset of symptoms in SOD1 rodents [86]. A significant upregulation of the ER stress-associated protein Puma was found in motoneurons of SOD1 (G93A) mice before symptom onset, and genetic deletion of Puma significantly improved motoneuron survival and delayed disease onset and motor dysfunction, suggesting that Puma plays an important role during the early stages of chronic neurodegeneration in vivo [79]. Other studies support that ER stress is linked to neurotoxicity associated with formation of inclusions of mutant SOD1 and plays an active role in the disease. A full UPR, including induction of stress sensor kinases, chaperones, and apoptotic mediators, was found in spinal cords of human patients with sporadic ALS, and the UPR chaperone PDI was detected in the cerebrospinal fluid (CSF) and was shown widely distributed throughout the motor neurons of these patients [86]. Furthermore, Nishitoh and colleagues provided evidences in a transgenic mice model that progression of familial ALS is affected by the ER stress-induced ASK1, which is activated by the specific interaction of mutant SOD1 with Derlin-1, a component of ERAD machinery [208].

ER stress induced by mutant SOD1 was found to trigger neuronal cell death. In L84V SOD1-expressing human neuroblastoma cells, in which oligomer formation is detected, ER stress was shown to cause the aggregation and inclusion bodies of mutant SOD1 and to induce neuronal death through activation of the ER-resident caspase-4 [209]. The $\mathrm{BH} 3$ only protein Bim has recently been shown to be a direct link between ER stress and mitochondria-mediated apoptosis in the Neuro2a cell line bearing mutant SOD1 inclusions [210]. Bim knockdown by siRNA significantly reduced nuclear apoptotic features in these inclusion-bearing cells and decreased both Bax recruitment to mitochondria and cytochrome $c$ release in a CHOP-independent manner. Calreticulin, a $\mathrm{Ca}^{2+}$-binding ER chaperone, was demonstrated in vitro and in vivo to play a critical link between the motoneuron-specific Fas/NO death pathway and the ER stress response induced by the mutant SOD1 (G93A) and point to a role of calreticulin levels in modulating motoneuron vulnerability to ALS. In vitro, decreased expression of calreticulin triggered SOD1 (G93A) motoneuron death through the Fas/NO pathway to induce an ER stress response that is restricted to and required for death of vulnerable SOD1 (G93A) motoneurons. In SOD1 (G93A) mice, reductions in calreticulin preceded muscle denervation and were restricted to vulnerable motor pools [211].

Caspase-12 activation was prevented, and life span was significantly extended, by X-linked Inhibitor of Apoptosis Protein (XIAP) overexpression in ALS transgenic mice carrying mutant SOD1 [212]. The small molecule SUN N8075, which has a marked protective effect on ER stress-induced cell death, was shown to slow disease progression and prolonged survival in mutant SOD1 transgenic mouse and rat models of ALS [213]. XBP1 deficiency dramatically decreased the toxicity of mutant SOD1 due to an enhanced clearance of mutant SOD1 aggregates by macroautophagy, a cellular pathway involved in lysosome-mediated protein degradation [214]. These observations were validated in vivo, in the mutant SOD1 transgenic mice with specific deletion of XBP1 in the nervous system that were shown to be more resistant to developing disease, correlating with increased levels of autophagy in motoneurons and reduced accumulation of mutant SOD1 aggregates in the spinal cord. It was demonstrated, both in vitro and in vivo, that the reticulon family of proteins regulates the ER chaperone PDI and that, through PDI, reticulon-4A (Nogo-A) can protect mice against the neurodegeneration that characterizes ALS [215]. It has been revealed that PDI has an important function in ameliorating mutant SOD1 aggregation and toxicity and that functional inhibition of PDI by S-nitrosylation may contribute to pathophysiology in both mutant SOD1-linked disease and sporadic ALS. In motor neuron-like NSC-34 cell lines transfected with SOD1 and PDI encoding vectors it was shown that overexpression of PDI decreases mutant SOD1 aggregation, inclusion formation, ER stress, and toxicity, whereas siRNA targeting PDI increased mutant SOD1 inclusion formation [216]. These findings are in accordance with previous results published by Atkin and coauthors [217] showing by proteomic analysis of the transgenic SOD1 (G93A) ALS rat model a significant upregulation of PDI family members in lumbar spinal cords, together with a significant upregulation of UPR mediators during disease progression. In NSC-34 cells PDI was found to colocalize with intracellular aggregates of mutant SOD1 and bound to both wild-type and mutant SOD1. An early upregulation of PDI was also observed in microglia of transgenic mutant SOD1 mice and increased expression of the UPR marker GADD34 in the spinal cord glia of these animals, showing that, in addition to neurons, UPR takes place in glial cells in ALS [218]. In BV-2 microglia, primary rat microglia, murine macrophages and human monocytes, UPR activated NADPH oxidase (NOX) with increased production of superoxide and increased release of TNF- $\alpha$, which were prevented by the pharmacological inhibition of PDI or its downregulation by siRNAs. Thus, results obtained by Jaronen and colleagues strongly demonstrate that UPR may lead to PDI-dependent NOX activation and contribute to neurotoxicity in ALS. In a 


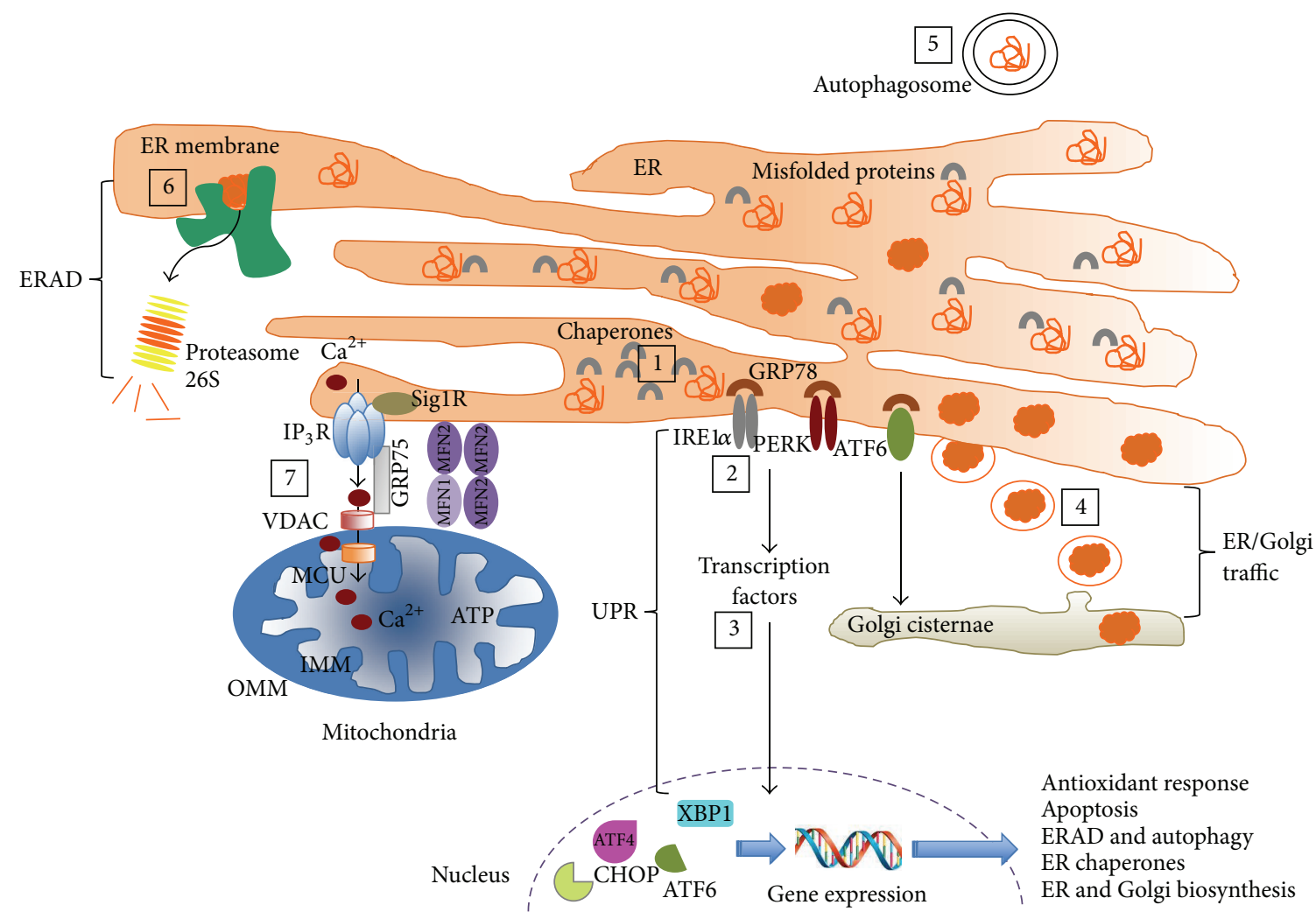

FIGURE 3: ER stress triggered by misfolded proteins in several neurodegenerative diseases. Abnormal conformations of the proteins $\mathrm{A} \beta /$ tau, $\alpha$ Syn, HTT, PrP, and SOD1/VAPB/FTD-43/FUS are implicated in the pathogenesis of AD, PD, HD, prion diseases, and ALS, respectively. Alterations in the function of ER chaperones and UPR-related components, ERAD, ER/Golgi trafficking, and ER-to-mitochondria Ca ${ }^{2+}$ transfer have been suggested as underlying mechanisms of ER stress triggered by these disease-associated proteins. These proteins can accumulate and aggregate at the ER and their stable interaction with ER chaperones such as GRP78 and PDI may trap ER chaperones, altering protein folding with concomitant ER stress (1). In addition, these proteins can lead to the oxidative modification of the active site of PDIs by nitrosylation leading to their enzymatic inactivation. Furthermore, some of these proteins alter the activity of the UPR stress sensors (IRE1 $\alpha$, PERK, and ATF6) (2) as well as the activity/levels of downstream signaling mediators and transcription factors (3), including cleaved ATF6, ATF4, and spliced XBP1. As a result, genes implicated in autophagy and ERAD, antioxidant response, ER chaperones, and organelle's biosynthesis are upregulated. Moreover, these proteins block the exit of vesicles from the ER and alter the trafficking between ER and Golgi of properly folded proteins (4). The cellular responses controlled by UPR transcription factors, including the modulation of autophagymediated degradation of protein aggregates (5), become compromised. Disease-related proteins can also interact with ERAD components (6), precluding the translocation of ERAD substrates from the ER to the cytosol, leading to the accumulation of abnormally folded proteins at the ER. Finally, $\mathrm{Ca}^{2+}$ released from the ER, mainly through the $\mathrm{IP}_{3} \mathrm{R}$, and its transfer to mitochondria can be impaired in the presence of disease-related proteins leading to mitochondrial $\mathrm{Ca}^{2+}$ overload and activation of apoptotic cell death pathways (7).

recent study, single-nucleotide polymorphisms (SNPs) in the P4HB gene, which encodes PDI, were associated with familial and sporadic ALS, suggesting that $\mathrm{P} 4 \mathrm{HB}$ is a modifier gene in ALS susceptibility [219].

Fused in sarcoma (FUS) is mutated in both sporadic and familial ALS patients [220]. The mechanisms underlying neurodegeneration are not fully understood, but FUS redistributes from the nucleus to the cytoplasm in affected motor neurons, where it triggers ER stress, as demonstrated in NSC-34 cells expressing mutant FUS [221]. PDI was shown to colocalize with mutant FUS in these motor neuron-like NSC-34 cells and in human ALS lumbar spinal cords, in both sporadic ALS and mutant FUS-linked familial ALS tissues [221]. Recent findings described new cellular mechanisms linking ALS with ataxin-2, a polyglutamine protein that normally contains 22 repeats but exhibits expanded repeats
(>34) in Spinocerebellar Ataxia, and provided further evidence that correlates disruption to ER-Golgi compartments and FUS pathology in ALS. Ataxin-2 with an intermediatelength repeat (Q31), which increases the risk of ALS [222], was shown to be a potent modifier of FUS pathology in cellular disease models, enhancing the translocation of FUS to the cytoplasm and inducing ER stress [223]. Ataxin-2 also colocalizes with FUS in the ER-Golgi compartments in neuronal cell lines leading to Golgi fragmentation, which is linked to neurodegeneration in ALS, and triggers the early stages of apoptosis.

Transactive response DNA-binding protein-43 (TDP-43) is a multifunctional nucleic acid-binding protein linked to several neurodegenerative diseases. Abnormal aggregates of TDP-43 and its hyperphosphorylated and N-terminal truncated C-terminal fragments (CTFs) are deposited as major 
components of ubiquitinated inclusions in most cases of ALS. TDP-43 overexpression was shown to increase the levels of CHOP, which was mediated by both mRNA upregulation and the attenuation of the degradation of the protein, and disruption of the CHOP gene markedly attenuated TDP43-induced cell death [224]. However, CHOP-mediated cell death induced by TDP-43 was shown to be independent of the PERK/eIF2 $\alpha /$ ATF4 or other pathway related to the UPR. The effects of mutant TDP-43 on the UPR were examined in transgenic rats that express mutant human TDP-43 restrictedly in the neurons of the forebrain, and a significant depletion of XBP1, followed by prominent accumulation of ubiquitin aggregates and Golgi fragments, was observed prior to neuronal loss [225]. However, these alterations occurred in the absence of upregulation of ER chaperones, and the mutation of TDP-43 failed to initiate the UPR. Recently, ALSassociated mutations in TDP-43 or the related RNA-binding protein FUS were shown to activate the UPR in C. elegans, with negative effects on neuronal function and lifespan [226].

A dominant mutation in the gene coding for the vesicleassociated membrane protein-associated protein B (VAPB) was associated with ALS. VAPB is an integral ER protein whose aminoterminus projects into the cytosol. Adenoassociated viral-mediated overexpression of both wild-type and mutant form of human VAPB was shown to selectively induce death of primary motor neurons, which was mediated by aberrant $\mathrm{Ca}^{2+}$ signals and ER stress-derived death pathways [227]. VAPB was recently identified as an MAM protein and to interact with the outer mitochondrial membrane protein tyrosine phosphatase-interacting protein 51 (PTPIP51). Moreover, loss of either VAPB or PTPIP51 was demonstrated to perturb uptake of $\mathrm{Ca}^{2+}$ by mitochondria following release from ER stores, and mutant VAPBP has been shown to exhibit altered binding to PTPIP51 and to increase ER-tomitochondria $\mathrm{Ca}^{2+}$ transfer upon ER release [228].

Sig1R is abnormally modified and contributes to the pathogenesis of ALS. In a recent study by Prause and colleagues, reduced levels of Sig1R protein were detected in lumbar ALS patient spinal cord, and Sig1R was abnormally accumulated in ER structures of motor neurons and colocalized with the 20S proteasome subunit. Sig1R accumulations were also observed in SOD1 transgenic mice, cultured ALS-8 patient's fibroblasts with the P56S-VAPB mutation, and in neuronal cell culture models. In these cell culture systems, the accumulation of Sig1R and several other proteins involved in protein quality control occurred concomitantly with severe disturbances in the UPR and impairment of protein degradation pathways. Furthermore, shRNA knockdown of Sig1R led to deranged $\mathrm{Ca}^{2+}$ signaling and caused abnormalities in ER and Golgi structures in cultured NSC-34 cells, and pharmacological activation of Sig1R induced the clearance of mutant protein aggregates in these cells [229], suggesting that Sig1R agonists can be promising therapeutic strategies for ALS.

Recent evidence links ER stress and $\mathrm{Ca}^{2+}$ deregulation with misfolding and aggregation of several ALS-associated proteins suggesting that motor deficits could be ameliorated if ER dysfunction could be prevented.

\section{Conclusion}

Endoplasmic reticulum (ER) stress plays an important role in a range of neurodegenerative disorders, including $\mathrm{AD}, \mathrm{PD}$, $\mathrm{HD}$, prion diseases, and ALS, characterized by intra- and/or extraneuronal accumulation of misfolded proteins and aggregates. Although ER dysfunction in these disorders is well recognized, the mechanisms by which it contributes to pathogenesis remain unclear. However, increasing evidence obtained using in vitro as well as in vivo disease models supports that alterations in ER homeostasis cause accumulation of disease-associated misfolded proteins, which in turn may initiate the ER stress response and contribute to synaptic and neuronal dysfunction in neurodegenerative diseases (Figure 3). Therefore, signaling components of the UPR and $\mathrm{ER} \mathrm{Ca}^{2+}$ signaling are emerging as potential targets for intervention, and so the treatment of a range of neurodegenerative disorders might become possible.

\section{References}

[1] A. R. English and G. K. Voeltz, "Endoplasmic reticulum structure and interconnections with other organelles," Cold Spring Harbor Perspectives in Biology, vol. 5, Article ID a013227, 2013.

[2] J. H. Lin, P. Walter, and T. S. B. Yen, "Endoplasmic reticulum stress in disease pathogenesis," Annual Review of Pathology, vol. 3, pp. 399-425, 2008.

[3] L. Ellgaard and A. Helenius, "Quality control in the endoplasmic reticulum," Nature Reviews Molecular Cell Biology, vol. 4, no. 3, pp. 181-191, 2003.

[4] S. S. Vembar and J. L. Brodsky, "One step at a time: endoplasmic reticulum-associated degradation," Nature Reviews Molecular Cell Biology, vol. 9, no. 12, pp. 944-957, 2008.

[5] T. Yorimitsu and D. J. Klionsky, "Eating the endoplasmic reticulum: quality control by autophagy," Trends in Cell Biology, vol. 17, no. 6, pp. 279-285, 2007.

[6] P. Walter and D. Ron, "The unfolded protein response: from stress pathway to homeostatic regulation," Science, vol. 334, no. 6059, pp. 1081-1086, 2011.

[7] D. Ron and P. Walter, "Signal integration in the endoplasmic reticulum unfolded protein response," Nature Reviews Molecular Cell Biology, vol. 8, no. 7, pp. 519-529, 2007.

[8] A. Bertolotti, Y. Zhang, L. M. Hendershot, H. P. Harding, and D. Ron, "Dynamic interaction of BiP and ER stress transducers in the unfolded-protein response," Nature Cell Biology, vol. 2, no. 6, pp. 326-332, 2000.

[9] J. S. Cox, C. E. Shamu, and P. Walter, "Transcriptional induction of genes encoding endoplasmic reticulum resident proteins requires a transmembrane protein kinase," Cell, vol. 73, no. 6, pp. 1197-1206, 1993.

[10] H. P. Harding, Y. Zhang, and D. Ron, "Protein translation and folding are coupled by an endoplasmic-reticulum-resident kinase," Nature, vol. 397, no. 271, p. 274, 1999.

[11] H. P. Harding, Y. Zhang, H. Zeng et al., "An integrated stress response regulates amino acid metabolism and resistance to oxidative stress," Molecular Cell, vol. 11, no. 3, pp. 619-633, 2003.

[12] S. B. Cullinan and J. A. Diehl, "PERK-dependent Activation of Nrf2 Contributes to Redox Homeostasis and Cell Survival following Endoplasmic Reticulum Stress," Journal of Biological Chemistry, vol. 279, no. 19, pp. 20108-20117, 2004. 
[13] K. Haze, H. Yoshida, H. Yanagi, T. Yura, and K. Mori, "Mammalian transcription factor ATF6 is synthesized as a transmembrane protein and activated by proteolysis in response to endoplasmic reticulum stress," Molecular Biology of the Cell, vol. 10, no. 11, pp. 3787-3799, 1999.

[14] K. Y. Tsang, D. Chan, J. F. Bateman, and K. S. E. Cheah, "In vivo cellular adaptation to ER stress: survival strategies with doubleedged consequences," Journal of Cell Science, vol. 123, no. 13, pp. 2145-2154, 2010.

[15] J.-P. Decuypere, G. Monaco, G. Bultynck, L. Missiaen, H. De Smedt, and J. B. Parys, "The IP3 receptor-mitochondria connection in apoptosis and autophagy," Biochimica et Biophysica Acta, vol. 1813, no. 5, pp. 1003-1013, 2011.

[16] S. Deegan, S. Saveljeva, A. M. Gorman, and A. Samali, "Stressinduced self-cannibalism: on the regulationof autophagy by endoplasmic reticulum stress," Cellular and Molecular Life Sciences. In press.

[17] I. Kim, W. Xu, and J. C. Reed, "Cell death and endoplasmic reticulum stress: disease relevance and therapeutic opportunities," Nature Reviews Drug Discovery, vol. 7, no. 12, pp. 1013-1030, 2008.

[18] M. J. Berridge, "The endoplasmic reticulum: a multifunctional signaling organelle," Cell Calcium, vol. 32, no. 5-6, pp. 235-249, 2002.

[19] I. Vandecaetsbeek, P. Vangheluwe, L. Raeymaekers, F. Wuytack, and J. Vanoevelen, "The Ca2+ pumps of the endoplasmic reticulum and Golgi apparatus," Cold Spring Harbor Perspectives in Biology, vol. 3, no. 5, Article ID a004184, 2011.

[20] R. Rizzuto, P. Pinton, W. Carrington et al., "Close contacts with the endoplasmic reticulum as determinants of mitochondrial Ca2+ responses," Science, vol. 280, no. 5370, pp. 1763-1766, 1998.

[21] C. Giorgi, D. De Stefani, A. Bononi, R. Rizzuto, and P. Pinton, "Structural and functional link between the mitochondrial network and the endoplasmic reticulum," International Journal of Biochemistry and Cell Biology, vol. 41, no. 10, pp. 1817-1827, 2009.

[22] P. Pizzo and T. Pozzan, "Mitochondria-endoplasmic reticulum choreography: structure and signaling dynamics," Trends in Cell Biology, vol. 17, no. 10, pp. 511-517, 2007.

[23] S. Patergnani, J. M. Suski, C. Agnoletto et al., "Calcium signaling around Mitochondria Associated Membranes (MAMs)," Cell Communication and Signaling, vol. 9, article 19, 2011.

[24] A. Bononi, S. Missiroli, F. Poletti et al., "Mitochondria-associated membranes (MAMs) as hotspot Ca2+ signaling units," Advances in Experimental Medicine and Biology, vol. 740, pp. 411-437, 2012.

[25] A. A. Rowland and G. K. Voeltz, "Endoplasmic reticulum-mitochondria contacts: function of the junction," Nature Reviews Molecular Cell Biology, vol. 13, pp. 607-625, 2012.

[26] A. Raturi and T. Simmen, "Where the endoplasmic reticulum and the mitochondrion tie the knot: the mitochondriaassociated membrane (MAM)," Biochimica Et Biophysica Acta, vol. 1833, pp. 213-224, 2013.

[27] M. Hamasaki, N. Furuta, A. Matsuda et al., "Autophagosomes form at ER-mitochondria contact sites," Nature, vol. 495, pp. 389-393, 2013.

[28] O. M. de Brito and L. Scorrano, "An intimate liaison: spatial organization of the endoplasmic reticulum-mitochondria relationship," EMBO Journal, vol. 29, no. 16, pp. 2715-2723, 2010.

[29] T. Hayashi, R. Rizzuto, G. Hajnoczky, and T.-P. Su, "MAM: more than just a housekeeper," Trends in Cell Biology, vol. 19, no. 2, pp. 81-88, 2009.
[30] C. Cárdenas, R. A. Miller, I. Smith et al., "Essential regulation of cell bioenergetics by constitutive InsP 3 receptor $\mathrm{Ca} 2+$ transfer to mitochondria," Cell, vol. 142, no. 2, pp. 270-283, 2010.

[31] T. Hayashi and T.-P. Su, "Sigma-1 receptor chaperones at the ER-mitochondrion interface regulate $\mathrm{Ca} 2+$ signaling and cell survival," Cell, vol. 131, no. 3, pp. 596-610, 2007.

[32] N. Shioda, K. Ishikawa, H. Tagashira, T. Ishizuka, H. Yawo, and K. Fukunaga, "Expression of a truncated form of the endoplasmic reticulum chaperone protein, $\sigma 1$ receptor, promotes mitochondrial energy depletion and apoptosis," Journal of Biological Chemistry, vol. 287, pp. 23318-23331, 2012.

[33] J. M. Vicencio, S. Lavandero, and G. Szabadkai, "Ca2+, autophagy and protein degradation: thrown off balance in neurodegenerative disease," Cell Calcium, vol. 47, no. 2, pp. 112-121, 2010.

[34] A. Criollo, M. C. Maiuri, E. Tasdemir et al., "Regulation of autophagy by the inositol trisphosphate receptor," Cell Death and Differentiation, vol. 14, no. 5, pp. 1029-1039, 2007.

[35] J. M. Vicencio, C. Ortiz, A. Criollo et al., "The inositol 1,4,5trisphosphate receptor regulates autophagy through its interaction with Beclin 1," Cell Death and Differentiation, vol. 16, no. 7, pp. 1006-1017, 2009.

[36] J.-P. Decuypere, K. Welkenhuyzen, T. Luyten et al., "Ins $(1,4,5) \mathrm{P} 3$ receptor-mediated $\mathrm{Ca} 2+$ signaling and autophagy induction are interrelated," Autophagy, vol. 7, no. 12, pp. 1472-1489, 2011.

[37] R. Sano, Y. C. Hou, M. Hedvat et al., "Endoplasmic reticulum protein $\mathrm{BI}-1$ regulates $\mathrm{Ca} 2+-$ mediated bioenergetics to promote autophagy," Genes and Development, vol. 26, pp. 1041-1054, 2012.

[38] S. E. Logue, P. Cleary, S. Saveljeva, and A. Samali, "New directions in ER stress-induced cell death," Apoptosis, vol. 18, pp. 537546, 2013.

[39] R. Bravo, T. Gutierrez, F. Paredes et al., "Endoplasmic reticulum: ER stress regulates mitochondrial bioenergetics," International Journal of Biochemistry and Cell Biology, vol. 44, no. 1, pp. 16-20, 2012.

[40] R. Bravo, J. M. Vicencio, V. Parra et al., "Increased ERmitochondrial coupling promotes mitochondrial respiration and bioenergetics during early phases of ER stress," Journal of Cell Science, vol. 124, no. 13, pp. 2143-2152, 2011.

[41] X. Wang, C. O. Eno, B. J. Altman et al., "ER stress modulates cellular metabolism," Biochemical Journal, vol. 435, no. 1, pp. 285-296, 2011.

[42] T. Simmen, J. E. Aslan, A. D. Blagoveshchenskaya et al., "PACS-2 controls endoplasmic reticulum-mitochondria communication and Bid-mediated apoptosis," EMBO Journal, vol. 24, no. 717, p. 729, 2005.

[43] T. Simmen, E. M. Lynes, K. Gesson, and G. Thomas, "Oxidative protein folding in the endoplasmic reticulum: tight links to the mitochondria-associated membrane (MAM)," Biochimica et Biophysica Acta, vol. 1798, no. 8, pp. 1465-1473, 2010.

[44] R. Jäger, M. J. Bertrand, A. M. Gorman, P. Vandenabeele, and A. Samali, "The unfolded protein response at the crossroads of cellular life and death during endoplasmic reticulum stress," Biology of the Cell, vol. 104, pp. 259-270, 2012.

[45] A. S. Treglia, S. Turco, L. Ulianich et al., "Cell fate following ER stress: just a matter of "quo ante" recovery or death?" Histology and Histopathology, vol. 27, no. 1, pp. 1-12, 2012.

[46] A. M. Gorman, S. J. M. Healy, R. Jäger, and A. Samali, "Stress management at the ER: regulators of ER stress-induced apoptosis," Pharmacology and Therapeutics, vol. 134, no. 3, pp. 306-316, 2012. 
[47] E. Szegezdi, U. Fitzgerald, and A. Samali, "Caspase-12 and ERstress-mMediated apoptosis: the story so far," Annals of the New York Academy of Sciences, vol. 1010, pp. 186-194, 2003.

[48] J. A. Martinez, Z. Zhang, S. I. Svetlov, R. L. Hayes, K. K. Wang, and S. F. Larner, "Calpain and caspase processing of caspase12 contribute to the ER stress-induced cell death pathway in differentiated PC12 cells," Apoptosis, vol. 15, no. 12, pp. 14801493, 2010.

[49] I. Tabas and D. Ron, "Integrating the mechanisms of apoptosis induced by endoplasmic reticulum stress," Nature Cell Biology, vol. 13, no. 3, pp. 184-190, 2011.

[50] H. Kim, H.-C. Tu, D. Ren et al., "Stepwise activation of BAX and BAK by tBID, BIM, and PUMA initiates mitochondrial apoptosis," Molecular Cell, vol. 36, no. 3, pp. 487-499, 2009.

[51] I. Novoa, H. Zeng, H. P. Harding, and D. Ron, "Feedback inhibition of the unfolded protein response by GADD34mediated dephosphorylation of eIF2 $\alpha$," Journal of Cell Biology, vol. 153, no. 5, pp. 1011-1021, 2001.

[52] M. H. Brush, D. C. Weiser, and S. Shenolikar, "Growth arrest and DNA damage-inducible protein GADD34 targets protein phosphatase $1 \alpha$ to the endoplasmic reticulum and promotes dephosphorylation of the $\alpha$ subunit of eukaryotic translation initiation factor 2," Molecular and Cellular Biology, vol. 23, no. 4, pp. 1292-1303, 2003.

[53] E. Kojima, A. Takeuchi, M. Haneda et al., "The function of GADD34 is a recovery from a shutoff of protein synthesis induced by ER stress: elucidation by GADD34-deficient mice," The FASEB Journal, vol. 17, no. 11, pp. 1573-1575, 2003.

[54] S. Y. Gilady, M. Bui, E. M. Lynes et al., "Erol $\alpha$ requires oxidizing and normoxic conditions to localize to the mitochondriaassociated membrane (MAM)," Cell Stress and Chaperones, vol. 15, no. 5, pp. 619-629, 2010.

[55] G. Li, M. Mongillo, K.-T. Chin et al., "Role of ERO1- $\alpha$-mediated stimulation of inositol 1,4,5-triphosphate receptor activity in endoplasmic reticulum stress-induced apoptosis," Journal of Cell Biology, vol. 186, no. 6, pp. 783-792, 2009.

[56] T. Yoneda, K. Imaizumi, K. Oono et al., "Activation of Caspase12, an endoplastic reticulum (ER) resident caspase, through tumor necrosis factor receptor-associated factor 2-dependent mechanism in response to the ER stress," Journal of Biological Chemistry, vol. 276, no. 17, pp. 13935-13940, 2001.

[57] D. Rodriguez, D. Rojas-Rivera, and C. Hetz, "Integrating stress signals at the endoplasmic reticulum: the BCL-2 protein family rheostat," Biochimica et Biophysica Acta, vol.1813, no. 4, pp. 564574, 2011.

[58] T. Szado, V. Vanderheyden, J. B. Parys et al., "Phosphorylation of inositol 1,4,5-trisphosphate receptors by protein kinase B/Akt inhibits Ca2+ release and apoptosis," Proceedings of the National Academy of Sciences of the United States of America, vol. 105, no. 7, pp. 2427-2432, 2008.

[59] S. Wang and W. S. El-Deiry, "Cytochrome c: a crosslink between the mitochondria and the endoplasmic reticulum in calciumdependent apoptosis," Cancer Biology and Therapy, vol. 3, no. 1, pp. 44-46, 2004.

[60] D. G. Breckenridge, M. Stojanovic, R. C. Marcellus, and G. C. Shore, "Caspase cleavage product of BAP31 induces mitochondrial fission through endoplasmic reticulum calcium signals, enhancing cytochrome c release to the cytosol," Journal of Cell Biology, vol. 160, no. 7, pp. 1115-1127, 2003.
[61] M. Germain, J. P. Mathai, H. M. McBride, and G. C. Shore, "Endoplasmic reticulum BIK initiates DRP1-regulated remodelling of mitochondrial cristae during apoptosis," EMBO Journal, vol. 24, no. 8, pp. 1546-1556, 2005.

[62] G. Szabadkai, A. M. Simoni, M. Chami, M. R. Wieckowski, R. J. Youle, and R. Rizzuto, "Drp-1-dependent division of the mitochondrial network blocks intraorganellar $\mathrm{Ca} 2+$ waves and protects against Ca2+-mediated apoptosis," Molecular Cell, vol. 16, no. 1, pp. 59-68, 2004.

[63] S. Wang and R. J. Kaufman, "The impact of the unfolded protein response on human disease," Journal of Cell Biology, vol. 197, pp. 857-867, 2012.

[64] S. Saxena and P. Caroni, "Selective neuronal vulnerability in neurodegenerative diseases: from stressor thresholds to degeneration," Neuron, vol. 71, no. 1, pp. 35-48, 2011.

[65] S. Mittal and S. Ganesh, "Protein quality control mechanisms and neurodegenerative disorders: checks, balances and deadlocks," Neuroscience Research, vol. 68, no. 3, pp. 159-166, 2010.

[66] M. Takalo, A. Salminen, H. Soininen, M. Hiltunen, and A. Haapasalo, "Protein aggregation and degradation mechanisms in neurodegenerative diseases," The American Journal of Neurodegenerative Disease, vol. 2, pp. 1-14, 2013.

[67] D. Chhangani and A. Mishra, "Protein quality controlsystem in neurodegeneration: a healing company hard to beat but failure is fatal," Molecular Neurobiology. In press.

[68] G. Mercado, P. Valdés, and C. Hetz, "An ERcentric view of Parkinson's disease," Trends in Molecular Medicine, vol. 19, pp. 165-175, 2013.

[69] C. A. Hetz and C. Soto, "Stressing out the ER: a role of the unfolded protein response in prion-related disorders," Current Molecular Medicine, vol. 6, no. 1, pp. 37-43, 2006.

[70] N. Naidoo, "ER and aging-Protein folding and the ER stress response," Ageing Research Reviews, vol. 8, no. 3, pp. 150-159, 2009.

[71] K. M. Doyle, D. Kennedy, A. M. Gorman, S. Gupta, S. J. M. Healy, and A. Samali, "Unfolded proteins and endoplasmic reticulum stress in neurodegenerative disorders," Journal of Cellular and Molecular Medicine, vol. 15, no. 10, pp. 2025-2039, 2011.

[72] S. Matus, L. H. Glimcher, and C. Hetz, "Protein folding stress in neurodegenerative diseases: a glimpse into the ER," Current Opinion in Cell Biology, vol. 23, no. 2, pp. 239-252, 2011.

[73] R. Vidal, B. Caballero, A. Couve, and C. Hetz, "Converging pathways in the occurrence of endoplasmic reticulum (ER) stress in Huntington's disease," Current Molecular Medicine, vol. 11, no. 1, pp. 1-12, 2011.

[74] M. K. Brown and N. Naidoo, "The endoplasmic reticulum stress response in aging and age-related diseases," Frontiers in Physiology, vol. 3, article 263, 2012.

[75] J. J. M. Hoozemans, E. S. Van Haastert, D. A. T. Nijholt, A. J. M. Rozemuller, and W. Scheper, "Activation of the unfolded protein response is an early event in Alzheimer's and Parkinson's disease," Neurodegenerative Diseases, vol. 10, no. 1-4, pp. 212215, 2012.

[76] B. D. Roussel, A. J. Kruppa, E. Miranda, D. C. Crowther, D. A. Lomas, and S. J. Marciniak, "Endoplasmic reticulum dysfunction in neurological disease," The Lancet Neurology, vol. 12, pp. 105-118, 2013.

[77] A. Carnemolla, E. Fossale, E. Agostoni et al., "Rrs1 is involved in endoplasmic reticulum stress response in huntington disease," Journal of Biological Chemistry, vol. 284, no. 27, pp. 18167-18173, 2009. 
[78] N. S. Rane, S.-W. Kang, O. Chakrabarti, L. Feigenbaum, and R. S. Hegde, "Reduced translocation of nascent prion protein during ER stress contributes to neurodegeneration," Developmental Cell, vol. 15, no. 3, pp. 359-370, 2008.

[79] D. Kieran, I. Woods, A. Villunger, A. Strasser, and J. H. M. Prehn, "Deletion of the BH3-only protein puma protects motoneurons from ER stress-induced apoptosis and delays motoneuron loss in ALS mice," Proceedings of the National Academy of Sciences of the United States of America, vol. 104, no. 51, pp. 20606-20611, 2007.

[80] A. Zuleta, R. L. Vidal, D. Armentano, G. Parsons, and C. Hetz, "AAV-mediated delivery of the transcription factor XBP1s into the striatum reduces mutant Huntingtin aggregation in a mouse model of Huntington's disease," Biochemical and Biophysical Research Communications, vol. 420, no. 3, pp. 558-563, 2012.

[81] J. J. M. Hoozemans, R. Veerhuis, E. S. Van Haastert et al., "The unfolded protein response is activated in Alzheimer's disease," Acta Neuropathologica, vol. 110, no. 2, pp. 165-172, 2005.

[82] J. J. M. Hoozemans, E. S. van Haastert, P. Eikelenboom, R. A. I. de Vos, J. M. Rozemuller, and W. Scheper, "Activation of the unfolded protein response in Parkinson's disease," Biochemical and Biophysical Research Communications, vol. 354, no. 3, pp. 707-711, 2007.

[83] J. J. M. Hoozemans, E. S. van Haastert, D. A. T. Nijholt, A. J. M. Rozemuller, P. Eikelenboom, and W. Scheper, "The unfolded protein response is activated in pretangle neurons in Alzheimer's disease hippocampus," The American Journal of Pathology, vol. 174, no. 4, pp. 1241-1251, 2009.

[84] E. V. Ilieva, V. Ayala, M. Jové et al., "Oxidative and endoplasmic reticulum stress interplay in sporadic amyotrophic lateral sclerosis," Brain, vol. 130, no. 12, pp. 3111-3123, 2007.

[85] W. Scheper, J. J. M. Hoozemans, C. C. Hoogenraad, A. J. M. Rozemuller, P. Eikelenboom, and F. Baas, "Rab6 is increased in Alzheimer's disease brain and correlates with endoplasmic reticulum stress," Neuropathology and Applied Neurobiology, vol. 33, no. 5, pp. 523-532, 2007.

[86] J. D. Atkin, M. A. Farg, A. K. Walker, C. McLean, D. Tomas, and M. K. Horne, "Endoplasmic reticulum stress and induction of the unfolded protein response in human sporadic amyotrophic lateral sclerosis," Neurobiology of Disease, vol. 30, no. 3, pp. 400407, 2008.

[87] Y. Ito, M. Yamada, H. Tanaka et al., "Involvement of CHOP, an ER-stress apoptotic mediator, in both human sporadic ALS and ALS model mice," Neurobiology of Disease, vol. 36, no. 3, pp. 470-476, 2009.

[88] K. J. Cho, B. I. Lee, S. Y. Cheon, H. W. Kim, H. J. Kim, and G. W. Kim, "Inhibition of apoptosis signal-regulating kinase 1 reduces endoplasmic reticulum stress and nuclear huntingtin fragments in a mouse model of Huntington disease," Neuroscience, vol.163, no. 4, pp. 1128-1134, 2009.

[89] H. Kraskiewicz and U. Fitzgerald, "InterfERing with endoplasmic reticulum stress," Trends in Pharmacological Sciences, vol. 33, no. 2, pp. 53-63, 2012.

[90] E. Ferreiro, I. Baldeiras, I. L. Ferreira et al., "Mitochondrialand endoplasmic reticulum-associated oxidative stress in Alzheimer's disease: from pathogenesis to biomarkers," International Journal of Cell Biology, vol. 2012, Article ID 735206, 23 pages, 2012.

[91] S. P. Selwood, S. Parvathy, B. Cordell et al., "Gene expression profile of the PDAPP mouse model for Alzheimer's disease with and without Apolipoprotein E," Neurobiology of Aging, vol. 30, no. 4, pp. 574-590, 2009.
[92] K. Ohta, A. Mizuno, S. Li et al., "Endoplasmic reticulum stress enhances $\gamma$-secretase activity," Biochemical and Biophysical Research Communications, vol. 416, no. 3-4, pp. 362-366, 2011.

[93] V. Muresan and Z. Muresan, "A persistent stress response to impeded axonal transport leads to accumulation of amyloid$\beta$ in the endoplasmic reticulum, and is a probable cause of sporadic Alzheimer's disease," Neurodegenerative Diseases, vol. 10, no. 1-4, pp. 60-63, 2012.

[94] K. Nishitsuji, T. Tomiyama, K. Ishibashi et al., "The E693A mutation in amyloid precursor protein increases intracellular accumulation of amyloid $\beta$ oligomers and causes endoplasmic reticulum stress-induced apoptosis in cultured cells," The American Journal of Pathology, vol. 174, no. 3, pp. 957-969, 2009.

[95] T. Umeda, T. Tomiyama, N. Sakama et al., "Intraneuronal amyloid $\beta$ oligomers cause cell death via endoplasmic reticulum stress, endosomal/lysosomal leakage, and mitochondrial dysfunction in vivo," Journal of Neuroscience Research, vol. 89, no. 7, pp. 1031-1042, 2011.

[96] M. Kaneko, H. Koike, R. Saito, Y. Kitamura, Y. Okuma, and Y. Nomura, "Loss of HRD1-mediated protein degradation causes amyloid precursor protein accumulation and amyloid- $\beta$ generation," Journal of Neuroscience, vol. 30, no. 11, pp. 3924-3932, 2010.

[97] O. Ghribi, M. M. Herman, P. Pramoonjago, N. K. Spaulding, and J. Savory, "GDNF regulates the $\mathrm{A} \beta$-induced endoplasmic reticulum stress response in rabbit hippocampus by inhibiting the activation of gadd 153 and the JNK and ERK kinases," Neurobiology of Disease, vol. 16, no. 2, pp. 417-427, 2004.

[98] K. Heinitz, M. Beck, R. Schliebs, and J. R. Perez-Polo, “Toxicity mediated by soluble oligomers of $\beta$-amyloid(1-42) on cholinergic SN56.B5.G4 cells," Journal of Neurochemistry, vol. 98, no. 6, pp. 1930-1945, 2006.

[99] S. M. Chafekar, R. Zwart, R. Veerhuis, H. Vanderstichele, F. Baas, and W. Scheper, "Increased A $\beta 1-42$ production sensitizes neuroblastoma cells for ER stress toxicity," Current Alzheimer Research, vol. 5, no. 5, pp. 469-474, 2008.

[100] Z.-Q. Ling, Q. Tian, L. Wang et al., "Constant illumination induces Alzheimer-like damages with endoplasmic reticulum involvement and the protection of melatonin," Journal of Alzheimer's Disease, vol. 16, no. 2, pp. 287-300, 2009.

[101] T. Nakagawa, H. Zhu, N. Morishima et al., "Caspase-12 mediates endoplasmic-reticulum-specific apoptosis and cytotoxicity by amyloid- $\beta$," Nature, vol. 403, no. 6765, pp. 98-103, 2000.

[102] J. Hitomi, T. Katayama, Y. Eguchi et al., "Involvement of caspase- 4 in endoplasmic reticulum stress-induced apoptosis and A $\beta$-induced cell death," Journal of Cell Biology, vol. 165, no. 3, pp. 347-356, 2004.

[103] S. Song, H. Lee, T.-I. Kam et al., "E2-25K/Hip-2 regulates caspase-12 in ER stress-mediated A $\beta$ neurotoxicity," Journal of Cell Biology, vol. 182, no. 4, pp. 675-684, 2008.

[104] R. J. S. Viana, C. J. Steer, and C. M. P. Rodrigues, "Amyloid- $\beta$ peptide-induced secretion of endoplasmic reticulum chaperone glycoprotein GRP94," Journal of Alzheimer's Disease, vol. 27, no. 1, pp. 61-73, 2011.

[105] R. Quiroz-Baez, P. Ferrera, R. Rosendo-Gutiérrez, J. Morán, F. Bermúdez-Rattoni, and C. Arias, "Caspase-12 activation is involved in amyloid- $\beta$ protein-induced synaptic toxicity," Journal of Alzheimer's Disease, vol. 26, no. 3, pp. 467-476, 2011.

[106] N. Soejima, Y. Ohyagi, N. Nakamura et al., "Intracellular accumulation of toxic turn amyloid-beta is associated with endoplasmic reticulum stress in Alzheimer's disease," Current Alzheimer Research, vol. 10, pp. 11-20, 2013. 
[107] C. S. Lai, J. Preisler, L. Baum et al., "Low molecular weight A $\beta$ induces collapse of endoplasmic reticulum," Molecular and Cellular Neuroscience, vol. 41, no. 1, pp. 32-43, 2009.

[108] K. I. Seyb, S. Ansar, J. Bean, and M. L. Michaelis, “ $\beta$-amyloid and endoplasmic reticulum stress reponses in primary neurons: effects of drugs that interact with the cytoskeleton," Journal of Molecular Neuroscience, vol. 28, no. 2, pp. 111-124, 2006.

[109] R. O. Costa, P. N. Lacor, I. L. Ferreira et al., "Endoplasmic reticulum stress occurs downstream of GluN2B subunit of Nmethyl-d-aspartate receptor in mature hippocampal cultures treated with amyloid-beta oligomers," Aging Cell, vol. 11, pp. 823-833, 2012.

[110] S. O. Yoon, D. J. Park, J. C. Ryu et al., "JNK3 perpetuates metabolic stress induced by Abeta peptides," Neuron, vol. 75, pp. 824-837, 2012.

[111] C. Supnet and I. Bezprozvanny, "The dysregulation of intracellular calcium in Alzheimer disease," Cell Calcium, vol. 47, no. 2, pp. 183-189, 2010.

[112] I. F. Smith, B. Hitt, K. N. Green, S. Oddo, and F. M. LaFerla, "Enhanced caffeine-induced ${ }^{\mathrm{Ca} 2+}$ release in the $3 \times \mathrm{Tg}$-AD mouse model of Alzheimer's disease," Journal of Neurochemistry, vol. 94, no. 6, pp. 1711-1718, 2005.

[113] W. W. Smith, H. Jiang, Z. Pei et al., "Endoplasmic reticulum stress and mitochondrial cell death pathways mediate A53T mutant alpha-synuclein-induced toxicity," Human Molecular Genetics, vol. 14, no. 24, pp. 3801-3811, 2005.

[114] G. E. Stutzmann, I. Smith, A. Caccamo, S. Oddo, F. M. LaFerla, and I. Parker, "Enhanced ryanodine receptor recruitment contributes to $\mathrm{Ca} 2+$ disruptions in young, adult, and aged Alzheimer's disease mice," Journal of Neuroscience, vol. 26, no. 19, pp. 5180-5189, 2006.

[115] S. Chakroborty, I. Goussakov, M. B. Miller, and G. E. Stutzmann, "Deviant ryanodine receptor-mediated calcium release resets synaptic homeostasis in presymptomatic 3xTg-AD mice," Journal of Neuroscience, vol. 29, no. 30, pp. 9458-9470, 2009.

[116] M. Müller, C. Cárdenas, L. Mei, K.-H. Cheung, and J. K. Foskett, "Constitutive cAMP response element binding protein (CREB) activation by Alzheimer's disease presenilin-driven inositol trisphosphate receptor (InsP3R) Ca2+ signaling," Proceedings of the National Academy of Sciences of the United States of America, vol. 108, no. 32, pp. 13293-13298, 2011.

[117] E. Copanaki, T. Schürmann, A. Eckert et al., "The amyloid precursor protein potentiates $\mathrm{CHOP}$ induction and cell death in response to ER Ca2+ depletion," Biochimica Et Biophysica Acta, vol. 1773, pp. 157-165, 2007.

[118] E. Ferreiro, C. R. Oliveira, and C. M. F. Pereira, "Involvement of endoplasmic reticulum $\mathrm{Ca} 2+$ release through ryanodine and inositol 1,4,5-triphosphate receptors in the neurotoxic effects induced by the amyloid- $\beta$ peptide," Journal of Neuroscience Research, vol. 76, no. 6, pp. 872-880, 2004.

[119] E. Ferreiro, R. Resende, R. Costa, C. R. Oliveira, and C. M. F. Pereira, "An endoplasmic-reticulum-specific apoptotic pathway is involved in prion and amyloid-beta peptides neurotoxicity," Neurobiology of Disease, vol. 23, no. 3, pp. 669-678, 2006.

[120] E. Ferreiro, C. R. Oliveira, and C. M. F. Pereira, "The release of calcium from the endoplasmic reticulum induced by amyloidbeta and prion peptides activates the mitochondrial apoptotic pathway," Neurobiology of Disease, vol. 30, no. 3, pp. 331-342, 2008.
[121] R. Resende, E. Ferreiro, C. Pereira, and C. Resende de Oliveira, "Neurotoxic effect of oligomeric and fibrillar species of amyloidbeta peptide 1-42: involvement of endoplasmic reticulum calcium release in oligomer-induced cell death," Neuroscience, vol. 155 , no. 3, pp. 725-737, 2008.

[122] R. O. Costa, E. Ferreiro, S. M. Cardoso, C. R. Oliveira, and C. M. F. Pereira, "ER stress-mediated apoptotic pathway induced by $\mathrm{A} \beta$ peptide requires the presence of functional mitochondria," Journal of Alzheimer's Disease, vol. 20, no. 2, pp. 625-636, 2010.

[123] L. Hedskog, C. M. Pinho, R. Filadi et al., "Modulation of the endoplasmic reticulum-mitochondria interface in Alzheimer's disease and related models," Proceedings of the National Academy of Sciences of the United States of America, vol. 110, pp. 7916-7921, 2013.

[124] R. O. Costa, E. Ferreiro, C. R. Oliveira, and C. M. Pereira, "Inhibition of mitochondrial cytochrome c oxidase potentiates $\mathrm{A} \beta$-induced ER stress and cell death in cortical neurons," Molecular and Cellular Neuroscience, vol. 52, pp. 1-8, 2013.

[125] R. O. Costa, E. Ferreiro, I. Martins et al., "Amyloid $\beta$-induced ER stress is enhanced under mitochondrial dysfunction conditions," Neurobiology of Aging, vol. 33, no. 4, pp. 824.e5-824.e16, 2012.

[126] R. Resende, E. Ferreiro, C. Pereira, and C. R. Oliveira, "ER stress is involved in $\mathrm{A} \beta$-induced GSK- $3 \beta$ activation and tau phosphorylation," Journal of Neuroscience Research, vol. 86, no. 9, pp. 2091-2099, 2008.

[127] C. Supnet, J. Grant, H. Kong, D. Westaway, and M. Mayne, "Amyloid- $\beta$-(1-42) increases ryanodine receptor-3 expression and function in neurons of TgCRND8 mice," Journal of Biological Chemistry, vol. 281, no. 50, pp. 38440-38447, 2006.

[128] A. Pannaccione, A. Secondo, P. Molinaro et al., "A new concept: a $\beta 1-42$ generates a hyperfunctional proteolytic NCX3 fragment that delays caspase-12 activation and neuronal death," Journal of Neuroscience, vol. 32, pp. 10609-10617, 2012.

[129] A. Ricobaraza, M. Cuadrado-Tejedor, A. Pérez-Mediavilla, D. Frechilla, J. Del Río, and A. García-Osta, "Phenylbutyrate ameliorates cognitive deficit and reduces tau pathology in an alzheimer's disease mouse model," Neuropsychopharmacology, vol. 34, no. 7, pp. 1721-1732, 2009.

[130] A. Ricobaraza, M. Cuadrado-Tejedor, S. Marco, I. Pérez-Otaño, and A. García-Osta, "Phenylbutyrate rescues dendritic spine loss associated with memory deficits in a mouse model of Alzheimer disease," Hippocampus, vol. 22, no. 5, pp. 1040-1050, 2012.

[131] A. Ricobaraza, M. Cuadrado-Tejedor, and A. Garcia-Osta, "Long-term phenylbutyrate administration prevents memory deficits in Tg2576 mice by decreasing Abeta," Frontiers in Bioscience, vol. 3, pp. 1375-1384, 2011.

[132] J. C. Wiley, J. S. Meabon, H. Frankowski et al., "Phenylbutyric acid rescues endoplasmic reticulum stress-induced suppression of APP proteolysis and prevents apoptosis in neuronal cells," PLoS ONE, vol. 5, no. 2, Article ID e9135, 2010.

[133] J. C. Wiley, C. Pettan-Brewer, and W. C. Ladiges, "Phenylbutyric acid reduces amyloid plaques and rescues cognitive behavior in AD transgenic mice," Aging Cell, vol. 10, no. 3, pp. 418-428, 2011.

[134] J. R. P. Prasanthi, T. Larson, J. Schommer, and O. Ghribi, "Silencing gadd153/chop gene expression protects against alzheimer's disease-like pathology induced by 27-hydroxycholesterol in rabbit hippocampus," PLoS ONE, vol. 6, no. 10, Article ID e26420, 2011. 
[135] D. Y. Lee, K.-S. Lee, H. J. Lee et al., "Activation of PERK signaling attenuates Abeta-mediated ER stress," PloS ONE, vol. 5, no. 5, p. e10489, 2010.

[136] S. Casas-Tinto, Y. Zhang, J. Sanchez-Garcia, M. GomezVelazquez, D. E. Rincon-Limas, and P. Fernandez-Funez, "The ER stress factor XBP1s prevents amyloid- $\beta$ neurotoxicity," Human Molecular Genetics, vol. 20, no. 11, Article ID ddr100, pp. 2144-2160, 2011.

[137] P. Yenki, F. Khodagholi, and F. Shaerzadeh, "Inhibition of phosphorylation of JNK suppresses Abeta-induced ER stress and upregulates prosurvival mitochondrial proteins in rat hippocampus," Journal of Molecular Neuroscience, vol. 49, pp. 262-269, 2013.

[138] A. Marrazzo, F. Caraci, E. T. Salinaro, T.-P. Su, A. Copani, and G. Ronsisvalle, "Neuroprotective effects of sigma-1 receptor agonists against beta-amyloid-induced toxicity," NeuroReport, vol. 16, no. 11, pp. 1223-1226, 2005.

[139] T. Maurice, T.-P. Su, and A. Privat, "Sigmal $(\sigma 1)$ receptor agonists and neurosteroids attenuate b25-35-amyloid peptideinduced amnesia in mice through a common mechanism," Neuroscience, vol. 83, no. 2, pp. 413-428, 1998.

[140] J. Meunier, J. Ieni, and T. Maurice, "The anti-amnesic and neuroprotective effects of donepezil against amyloid B25-35 peptide-induced toxicity in mice involve an interaction with the $\sigma 1$ receptor," British Journal of Pharmacology, vol. 149, no. 8, pp. 998-1012, 2006.

[141] V. Antonini, A. Marrazzo, G. Kleiner et al., "Anti-amnesic and neuroprotective actions of the sigma-1 receptor agonist (-)MR22 in rats with selective cholinergic lesion and amyloid infusion," Journal of Alzheimer's Disease, vol. 24, no. 3, pp. 569586, 2011.

[142] K. Iqbal, F. Liu, C.-X. Gong, and I. Grundke-Iqbal, "Tau in Alzheimer disease and related tauopathies," Current Alzheimer Research, vol. 7, no. 8, pp. 656-664, 2010.

[143] M. Morris, S. Maeda, K. Vossel, and L. Mucke, "The many faces of Tau," Neuron, vol. 70, no. 3, pp. 410-426, 2011.

[144] C. Ballatore, V. M. Lee, and J. Q. Trojanowski, “Tau-mediated neurodegeneration in Alzheimer's disease and related disorders," Nature Reviews Neuroscience, vol. 8, no. 9, pp. 663-672, 2007.

[145] E. Ferreiro and C. M. F. Pereira, "Endoplasmic reticulum stress: a new playER in tauopathies," Journal of Pathology, vol. 226, no. 5, pp. 687-692, 2012.

[146] J. J. Hoozemans and W. Scheper, "Endoplasmic reticulum: the unfolded protein response is tangled in neurodegeneration," International Journal of Biochemistry \& Cell Biology, vol. 44, no. 8, pp. 1295-1298, 2012.

[147] D. A. T. Nijholt, E. S. van Haastert, A. J. M. Rozemuller, W. Scheper, and J. J. M. Hoozemans, "The unfolded protein response is associated with early tau pathology in the hippocampus of tauopathies," Journal of Pathology, vol. 226, no. 5, pp. 693-702, 2012.

[148] Y.-S. Ho, X. Yang, J. C.-F. Lau et al., "Endoplasmic reticulum stress induces tau pathology and forms a vicious cycle: implication in Alzheimer's disease pathogenesis," Journal of Alzheimer's Disease, vol. 28, no. 4, pp. 839-854, 2012.

[149] Z.-C. Liu, Z.-Q. Fu, J. Song et al., "Bip enhanced the association of GSK- $3 \beta$ with Tau during ER stress both in vivo and in vitro," Journal of Alzheimer's Disease, vol. 29, no. 4, pp. 727-740, 2012.

[150] Z.-Q. Fu, Y. Yang, J. Song et al., "LiCl attenuates thapsigargininduced tau hyperphosphorylation by inhibiting GSK-3 $\beta$ in vivo and in vitro," Journal of Alzheimer's Disease, vol. 21, no. 4, pp. 1107-1117, 2010.

[151] X. A. Liu, J. Song, Q. Jiang, Q. Wang, Q. Tian, and J. Z. Wang, "Expression of the hyperphosphorylated tau attenuates ER stress-induced apoptosis with upregulation of unfolded protein response," Apoptosis, vol. 17, pp. 1039-1049, 2012.

[152] Y. Sakagami, T. Kudo, H. Tanimukai et al., "Involvement of endoplasmic reticulum stress in tauopathy," Biochemical and Biophysical Research Communications, vol. 430, pp. 500-504, 2013.

[153] D. A. Nijholt, A. Nölle, E. S. van Haastert et al., "Unfolded protein response activates glycogen synthase kinase-3 via selective lysosomal degradation," Neurobiology of Aging, vol. 34, no. 7, pp. 1759-1771, 2013.

[154] C. A. Loewen and M. B. Feany, "The unfolded protein response protects from tau neurotoxicity in vivo," PLoS ONE, vol. 5, no. 9, Article ID el3084, 2010.

[155] A. Bellucci, L. Navarria, M. Zaltieri et al., "Induction of the unfolded protein response by $\alpha$-synuclein in experimental models of Parkinson's disease," Journal of Neurochemistry, vol. 116, no. 4, pp. 588-605, 2011.

[156] M. S. Gorbatyuk, A. Shabashvili, W. Chen et al., "Glucose regulated protein 78 diminishes $\alpha$-Synuclein neurotoxicity in a rat model of Parkinson disease," Molecular Therapy, vol. 20, pp. 1327-1337, 2012.

[157] I. Ferrer, A. Martinez, R. Blanco, E. Dalfó, and M. Carmona, "Neuropathology of sporadic Parkinson disease before the appearance of parkinsonism: preclinical Parkinson disease," Journal of Neural Transmission, vol. 118, no. 5, pp. 821-839, 2011.

[158] S. Ito, K. Nakaso, K. Imamura, T. Takeshima, and K. Nakashima, "Endogenous catecholamine enhances the dysfunction of unfolded protein response and $\alpha$-synuclein oligomerization in PC12 cells overexpressing human $\alpha$-synuclein," Neuroscience Research, vol. 66, no. 1, pp. 124-130, 2010.

[159] T. Calì, D. Ottolini, A. Negro, and M. Brini, " $\alpha$-Synuclein controls mitochondrial calcium homeostasis by enhancing endoplasmic reticulum-mitochondria interactions," Journal of Biological Chemistry, vol. 287, pp. 17914-17929, 2012.

[160] C. Belal, N. J. Ameli, A. El kommos et al., "The homocysteineinducible endoplasmic reticulum (ER) stress protein herp counteracts mutant $\alpha$-synuclein-induced ER stress via the homeostatic regulation of ER-resident calcium release channel proteins," Human Molecular Genetics, vol. 21, no. 5, pp. 963-977, 2012.

[161] E. Colla, P. Coune, Y. Liu et al., "Endoplasmic reticulum stress is important for the manifestations of $\alpha$-synucleinopathy in vivo," Journal of Neuroscience, vol. 32, no. 10, pp. 3306-3320, 2012.

[162] P. Jiang, M. Gan, A. S. Ebrahim, W.-L. Lin, H. L. Melrose, and S.-H. C. Yen, "ER stress response plays an important role in aggregation of alpha-synuclein," Molecular Neurodegeneration, vol. 5, no. 1, article 56, 2010.

[163] E. Colla, P. H. Jensen, O. Pletnikova, J. C. Troncoso, C. Glabe, and M. K. Lee, "Accumulation of toxic $\alpha$-synuclein oligomer within endoplasmic reticulum occurs in $\alpha$-synucleinopathy in vivo," Journal of Neuroscience, vol. 32, no. 10, pp. 3301-3305, 2012.

[164] H. Cheng, L. Wang, and C.-C. Wang, "Domain a of protein disulfide isomerase plays key role in inhibiting $\alpha$-synuclein fibril formation," Cell Stress and Chaperones, vol. 15, no. 4, pp. 415$421,2010$.

[165] K. Xu and X.-P. Zhu, "Endoplasmic reticulum stress and prion diseases," Reviews in the Neurosciences, vol. 23, no. 1, pp. 79-84, 2012. 
[166] A. Aguzzi and J. Falsig, "Prion propagation, toxicity and degradation," Nature Neuroscience, vol. 15, pp. 936-939, 2012.

[167] C. Hetz, J. Castilla, and C. Soto, "Perturbation of endoplasmic reticulum homeostasis facilitates prion replication," Journal of Biological Chemistry, vol. 282, no. 17, pp. 12725-12733, 2007.

[168] C. Hetz, M. Russelakis-Carneiro, K. Maundrell, J. Castilla, and C. Soto, "Caspase-12 and endoplasmic reticulum stress mediate neurotoxicity of pathological prion protein," EMBO Journal, vol. 22, no. 20, pp. 5435-5445, 2003.

[169] C. Hetz, M. Russelakis-Carneiro, S. Wälchli et al., "The disulfide isomerase Grp58 is a protective factor against prion neurotoxicity," Journal of Neuroscience, vol. 25, no. 11, pp. 2793-2802, 2005.

[170] M. Torres, G. Encina, C. Soto, and C. Hetz, "Abnormal calcium homeostasis and protein folding stress at the ER: a common factor in familial and infectious prion disorders," Communicative and Integrative Biology, vol. 4, no. 3, pp. 258-261, 2011.

[171] C. Lazzari, C. Peggion, R. Stella et al., "Cellular prion protein is implicated in the regulation of local $\mathrm{Ca} 2+$ movements in cerebellar granule neurons," Journal of Neurochemistry, vol. 116, no. 5, pp. 881-890, 2011.

[172] A. D. Powell, E. C. Toescu, J. Collinge, and J. G. R. Jefferys, "Alterations in Ca2+-buffering in prion-null mice: association with reduced afterhyperpolarizations in CA1 hippocampal neurons," Journal of Neuroscience, vol. 28, no. 15, pp. 3877-3886, 2008.

[173] M. Torres, K. Castillo, R. Armisén, A. Stutzin, C. Soto, and C. Hetz, "Prion protein misfolding affects calcium homeostasis and sensitizes cells to endoplasmic reticulum stress," PLOS ONE, vol. 5, no. 12, Article ID e15658, 2010.

[174] E. Ferreiro, R. Costa, S. Marques, S. M. Cardoso, C. R. Oliveira, and C. M. F. Pereira, "Involvement of mitochondria in endoplasmic reticulum stress-induced apoptotic cell death pathway triggered by the prion peptide PrP 106-126," Journal of Neurochemistry, vol. 104, no. 3, pp. 766-776, 2008.

[175] E. Cohen, D. Avrahami, K. Frid et al., "Snord 3A: a molecular marker and modulator of prion disease progression," PLoS One, vol. 8, Article ID e54433, 2013.

[176] J. A. Moreno, H. Radford, D. Peretti et al., "Sustained translational repression by eIF $2 \alpha$-P mediates prion neurodegeneration," Nature, vol. 485, pp. 507-511, 2012.

[177] C. Hetz, A.-H. Lee, D. Gonzalez-Romero et al., "Unfolded protein response transcription factor XBP-1 does not influence prion replication or pathogenesis," Proceedings of the National Academy of Sciences of the United States of America, vol. 105, no. 2, pp. 757-762, 2008.

[178] M. Nunziante, K. Ackermann, K. Dietrich et al., "Proteasomal dysfunction and endoplasmic reticulum stress enhance trafficking of prion protein aggregates through the secretory pathway and increase accumulation of pathologic prion protein," Journal of Biological Chemistry, vol. 286, no. 39, pp. 33942-33953, 2011.

[179] S. B. Wang, Q. Shi, Y. Xu et al., "Protein disulfide isomerase regulates endoplasmic reticulum stress and the apoptotic process during prion infection and PrP mutant-induced cytotoxicity," PLoS One, vol. 7, Article ID e38221, 2012.

[180] Q. Shi and X.-P. Dong, "CtmPrP and ER stress: a neurotoxic mechanism of some special PrP mutants," Prion, vol. 5, no. 3, pp. 123-125, 2011.

[181] X. Wang, Q. Shi, K. Xu et al., "Familial CJD associated PrP mutants within transmembrane region induced CTM-PrP retention in ER and Triggered apoptosis by ER stress in SHSY5Y cells," PLoS ONE, vol. 6, no. 1, Article ID e14602, 2011.
[182] E. Quaglio, E. Restelli, A. Garofoli et al., "Expression of mutant or cytosolic PrP in transgenic mice and cells is not associated with endoplasmic reticulum stress or proteasome dysfunction," PLoS ONE, vol. 6, no. 4, Article ID e19339, 2011.

[183] C. A. Ross and S. J. Tabrizi, "Huntington's disease: from molecular pathogenesis to clinical treatment," The Lancet Neurology, vol. 10, no. 1, pp. 83-98, 2011.

[184] R. S. Atwal, J. Xia, D. Pinchev, J. Taylor, R. M. Epand, and R. Truant, "Huntingtin has a membrane association signal that can modulate huntingtin aggregation, nuclear entry and toxicity," Human Molecular Genetics, vol. 16, no. 21, pp. 2600-2615, 2007.

[185] R. S. Atwal and R. Truant, "A stress sensitive ER membraneassociation domain in Huntingtin protein defines a potential role for Huntingtin in the regulation of autophagy," Autophagy, vol. 4, no. 1, pp. 91-93, 2008.

[186] T. Maiuri, T. Woloshansky, J. Xia, and R. Truant, “. The huntingtin N17 domain is a multifunctional CRM1 and Randependent nuclear and cilial export signal," Human Molecular Genetics, vol. 22, no. 7, pp. 1383-1394, 2013.

[187] J.-Y. Noh, H. Lee, S. Song et al., "SCAMP5 links endoplasmic reticulum stress to the accumulation of expanded polyglutamine protein aggregates via endocytosis inhibition," Journal of Biological Chemistry, vol. 284, no. 17, pp. 11318-11325, 2009.

[188] H. Lee, J.-Y. Noh, Y. Oh et al., "IRE1 plays an essential role in ER stress-mediated aggregation of mutant huntingtin via the inhibition of autophagy flux," Human Molecular Genetics, vol. 21, no. 1, pp. 101-114, 2012.

[189] T. Ratovitski, E. Chighladze, N. Arbez et al., "Huntingtin protein interactions altered by polyglutamine expansion as determined by quantitative proteomic analysis," Cell Cycle, vol. 11, pp. 20062021, 2012.

[190] S. Reijonen, N. Putkonen, A. Nørremølle, D. Lindholm, and L. Korhonen, "Inhibition of endoplasmic reticulum stress counteracts neuronal cell death and protein aggregation caused by N-terminal mutant huntingtin proteins," Experimental Cell Research, vol. 314, no. 5, pp. 950-960, 2008.

[191] R. Leon, N. Bhagavatula, O. Ulukpo, M. McCollum, and J. Wei, "BimEL as a possible molecular link between proteasome dysfunction and cell death induced by mutant huntingtin," European Journal of Neuroscience, vol. 31, no. 11, pp. 1915-1925, 2010.

[192] P. Lajoie and E. L. Snapp, "Changes in BiP availability reveal hypersensitivity to acute endoplasmic reticulum stress in cells expressing mutant huntingtin," Journal of Cell Science, vol. 124, no. 19, pp. 3332-3343, 2011.

[193] Y. Jiang, H. Lv, M. Liao et al., "GRP78 counteracts cell death and protein aggregation caused by mutant huntingtin proteins," Neuroscience Letters, vol. 516, no. 2, pp. 182-187, 2012.

[194] M. L. Duennwald and S. Lindquist, "Impaired ERAD and ER stress are early and specific events in polyglutamine toxicity," Genes and Development, vol. 22, no. 23, pp. 3308-3319, 2008.

[195] H. Yang, C. Liu, Y. Zhong, S. Luo, M. J. Monteiro, and S. Fang, "Huntingtin interacts with the cue domain of gp78 and inhibits gp78 binding to ubiquitin and p97/VCP," PLoS ONE, vol. 5, no. 1, Article ID e8905, 2010.

[196] R. L. Vidal, A. Figueroa, F. A. Court et al., "Targeting the UPR transcription factor XBP1 protects against Huntington's disease through the regulation of FoxO1 and autophagy," Human Molecular Genetics, vol. 21, no. 10, pp. 2245-2262, 2012.

[197] T.-S. Tang, H. Tu, E. Y. W. Chan et al., "Huntingtin and huntingtin-associated protein 1 influence neuronal calcium 
signaling mediated by inositol- $(1,4,5)$ triphosphate receptor type 1," Neuron, vol. 39, no. 2, pp. 227-239, 2003.

[198] T.-S. Tang, C. Guo, H. Wang, X. Chen, and I. Bezprozvanny, "Neuroprotective effects of inositol 1,4,5-trisphosphate receptor C-terminal fragment in a Huntington's disease mouse model," Journal of Neuroscience, vol. 29, no. 5, pp. 1257-1266, 2009.

[199] X. Chen, J. Wu, S. Lvovskaya, E. Herndon, C. Supnet, and I. Bezprozvanny, "Dantrolene is neuroprotective in Huntington's disease transgenic mouse model," Molecular Neurodegeneration, vol. 6, no. 1, article 81, 2011.

[200] M. Suzuki, Y. Nagai, K. Wada, and T. Koike, "Calcium leak through ryanodine receptor is involved in neuronal death induced by mutant huntingtin," Biochemical and Biophysical Research Communications, vol. 429, pp. 18-23, 2012.

[201] A. C. Ludolph, J. Brettschneider, and J. H. Weishaupt, "Amyotrophic lateral sclerosis," Current Opinion in Neurology, vol. 201225, pp. 530-535.

[202] A. K. Walker and J. D. Atkin, "Stress signaling from the endoplasmic reticulum: a central player in the pathogenesis of amyotrophic lateral sclerosis," IUBMB Life, vol. 63, no. 9, pp. 754763, 2011.

[203] J. Lautenschlaeger, T. Prell, and J. Grosskreutz, "Endoplasmic reticulum stress and the ER mitochondrial calcium cycle in amyotrophic lateral sclerosis," Amyotrophic Lateral Sclerosis, vol. 13, no. 2, pp. 166-177, 2012.

[204] H. Kikuchi, G. Almer, S. Yamashita et al., "Spinal cord endoplasmic reticulum stress associated with a microsomal accumulation of mutant superoxide dismutase-1 in an ALS model," Proceedings of the National Academy of Sciences of the United States of America, vol. 103, no. 15, pp. 6025-6030, 2006.

[205] T. Nagata, H. Ilieva, T. Murakami et al., "Increased ER stress during motor neuron degeneration in a transgenic mouse model of amyotrophic lateral sclerosis," Neurological Research, vol. 29, no. 8, pp. 767-771, 2007.

[206] Y. K. Oh, K. S. Shin, J. Yuan, and S. J. Kang, "Superoxide dismutase 1 mutants related to amyotrophic lateral sclerosis induce endoplasmic stress in neuro2a cells," Journal of Neurochemistry, vol. 104, no. 4, pp. 993-1005, 2008.

[207] T. Prell, J. Lautenschläger, O. W. Witte, M. T. Carri, and J. Grosskreutz, "The unfolded protein response in models of human mutant G93A amyotrophic lateral sclerosis," European Journal of Neuroscience, vol. 35, no. 5, pp. 652-660, 2012.

[208] H. Nishitoh, H. Kadowaki, A. Nagai et al., "ALS-linked mutant SOD1 induces ER stress- and ASK1-dependent motor neuron death by targeting Derlin-1," Genes and Development, vol. 22, no. 11, pp. 1451-1464, 2008.

[209] Y. Koyama, T. Hiratsuka, S. Matsuzaki et al., "Familiar amyotrophic lateral sclerosis (FALS)-linked SOD1 mutation accelerates neuronal cell death by activating cleavage of caspase- 4 under ER stress in an in vitro model of FALS," Neurochemistry International, vol. 57, no. 7, pp. 838-843, 2010.

[210] K. Y. Soo, J. D. Atkin, M. Farg, A. K. Walker, M. K. Horne, and P. Nagley, "Bim links ER stress and apoptosis in cells expressing mutant SOD1 associated with amyotrophic lateral sclerosis," PLoS ONE, vol. 7, no. 4, Article ID e35413, 2012.

[211] N. Bernard-Marissal, A. Moumen, C. Sunyach et al., "Reduced calreticulin levels link endoplasmic reticulum stress and fastriggered cell death in motoneurons vulnerable to ALS," Journal of Neuroscience, vol. 32, no. 14, pp. 4901-4912, 2012.

[212] H. Wootz, I. Hansson, L. Korhonen, and D. Lindholm, "XIAP decreases caspase- 12 cleavage and calpain activity in spinal cord of ALS transgenic mice," Experimental Cell Research, vol. 312, no. 10, pp. 1890-1898, 2006.

[213] M. Shimazawa, H. Tanaka, Y. Ito et al., "An Inducer of VGF protects cells against ER stress-induced cell death and prolongs survival in the mutant SOD1 animal Models of Familial ALS," PLoS ONE, vol. 5, no. 12, Article ID e15307, 2010.

[214] C. Hetz, P. Thielen, S. Matus et al., "XBP-1 deficiency in the nervous system protects against amyotrophic lateral sclerosis by increasing autophagy," Genes and Development, vol. 23, no. 19, pp. 2294-2306, 2009.

[215] Y. S. Yang, N. Y. Harel, and S. M. Strittmatter, "Reticulon-4A (Nogo-A) redistributes protein disulfide isomerase to protect mice from SOD1-dependent amyotrophic lateral sclerosis," Journal of Neuroscience, vol. 29, no. 44, pp. 13850-13859, 2009.

[216] A. K. Walker, M. A. Farg, C. R. Bye, C. A. McLean, M. K. Horne, and J. D. Atkin, "Protein disulphide isomerase protects against protein aggregation and is S-nitrosylated in amyotrophic lateral sclerosis," Brain, vol. 133, no. 1, pp. 105-116, 2010.

[217] J. D. Atkin, M. A. Farg, B. J. Turner et al., "Induction of the unfolded protein response in familial amyotrophic lateral sclerosis and association of protein-disulfide isomerase with superoxide dismutase 1," Journal of Biological Chemistry, vol. 281, no. 40, pp. 30152-30165, 2006.

[218] M. Jaronen, P. Vehviläinen, T. Malm et al., "Protein disulfide isomerase in ALS mouse glia links protein misfolding with NADPH oxidase-catalyzed superoxide production," Human Molecular Genetics, vol. 22, pp. 646-655, 2013.

[219] C. T. Kwok, A. G. Morris, J. Frampton, B. Smith, C. E. Shaw, and J. de Belleroche, "Association studies indicate that protein disulfide isomerase is a risk factor in amyotrophic lateral sclerosis," Free Radical Biology and Medicine, vol. 58C, pp. 8186, 2013.

[220] S. Da Cruz and D. W. Cleveland, "Understanding the role of TDP-43 and FUS/TLS in ALS and beyond," Current Opinion in Neurobiology, vol. 21, no. 6, pp. 904-919, 2011.

[221] M. A. Farg, K. Y. Soo, A. K. Walker et al., "Mutant FUS induces endoplasmic reticulum stress in amyotrophic lateral sclerosis and interacts with protein disulfide-isomerase," Neurobiology of Aging, vol. 33, pp. 2855-2868, 2012.

[222] A. C. Elden, H.-J. Kim, M. P. Hart et al., "Ataxin-2 intermediatelength polyglutamine expansions are associated with increased risk for ALS," Nature, vol. 466, no. 7310, pp. 1069-1075, 2010.

[223] M. A. Farg, K. Y. Soo, S. T. Warraich, V. Sundaramoorthy, I. P. Blair, and J. D. Atkin, "Ataxin-2 interacts with FUS and intermediate-length polyglutamine expansions enhance FUSrelated pathology in amyotrophic lateral sclerosis," Human Molecular Genetics, vol. 22, pp. 717-728, 2013.

[224] H. Suzuki and M. Matsuoka, "TDP-43 toxicity is mediated by the unfolded protein response-unrelated induction of C/EBP homologous protein expression," Journal of Neuroscience Research, vol. 90, no. 3, pp. 641-647, 2012.

[225] J. Tong, C. Huang, F. Bi, Q. Wu, B. Huang, and H. Zhou, "XBP1 depletion precedes ubiquitin aggregation and Golgi fragmentation in TDP-43 transgenic rats," Journal of Neurochemistry, vol. 123, pp. 406-416, 2012.

[226] A. Vaccaro, A. Tauffenberger, P. E. Ash, Y. Carlomagno, L. Petrucelli, and J. A. Parker, "TDP-1/TDP-43 regulates stress signaling and age-dependent proteotoxicity in Caenorhabditis elegans," PLOS Genetics, vol. 8, Article ID e1002806, 2012.

[227] K. Langou, A. Moumen, C. Pellegrino et al., "AAV-mediated expression of wild-type and ALS-linked mutant VAPB selectively triggers death of motoneurons through a ${ }^{\mathrm{Ca} 2+}$-dependent 
ER-associated pathway," Journal of Neurochemistry, vol. 114, no. 3, pp. 795-809, 2010.

[228] K. J. De vos, G. M. Mórotz, R. Stoica et al., "VAPB interacts with the mitochondrial protein PTPIP51 to regulate calcium homeostasis," Human Molecular Genetics, vol. 21, no. 6, pp. 1299-1311, 2012.

[229] J. Prause, A. Goswami, I. Katona et al., "Altered localization, abnormal modification and loss of function of Sigma receptor1 in amyotrophic lateral sclerosis," Human Molecular Genetics, vol. 22, pp. 1581-1600, 2013. 

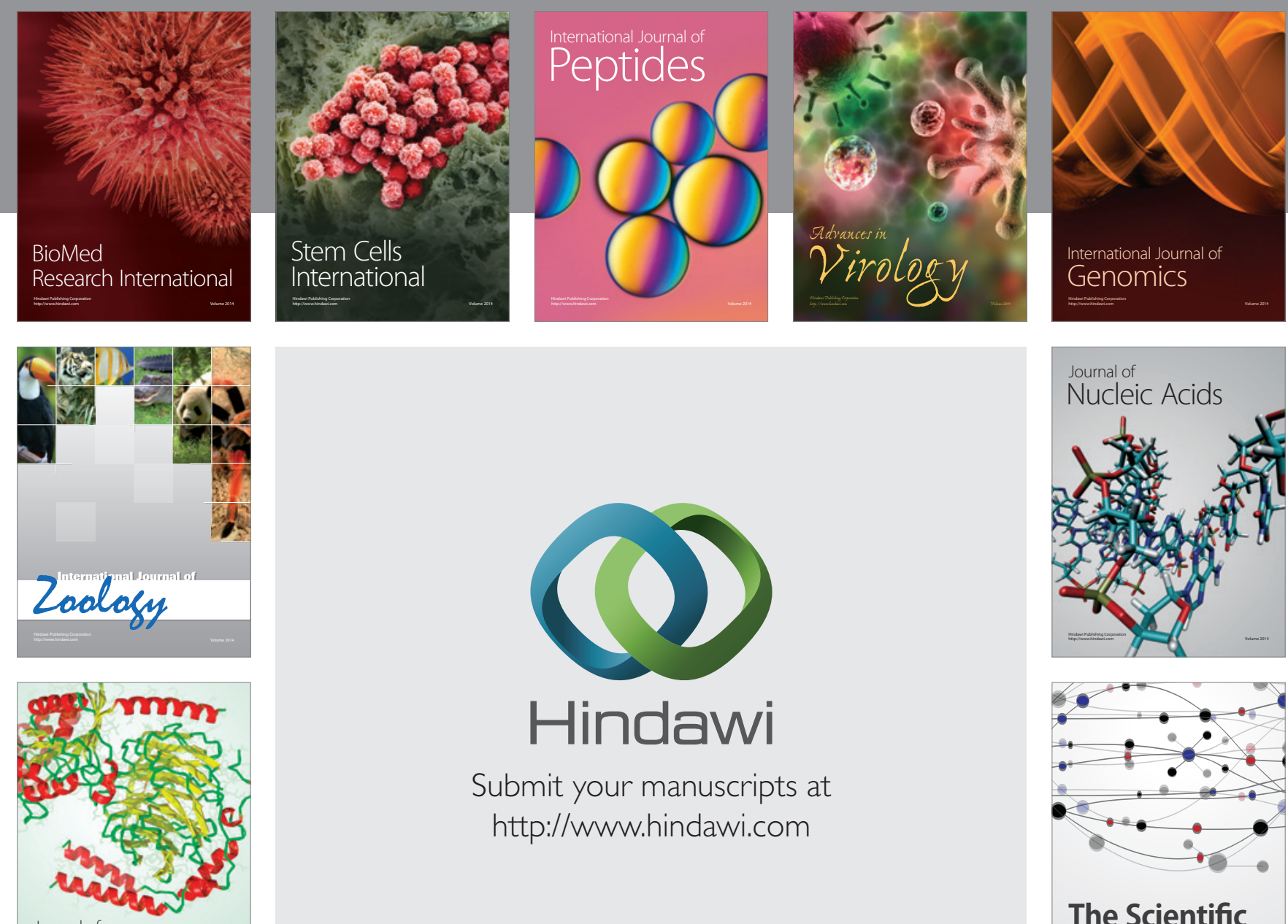

Submit your manuscripts at

http://www.hindawi.com

Journal of
Signal Transduction
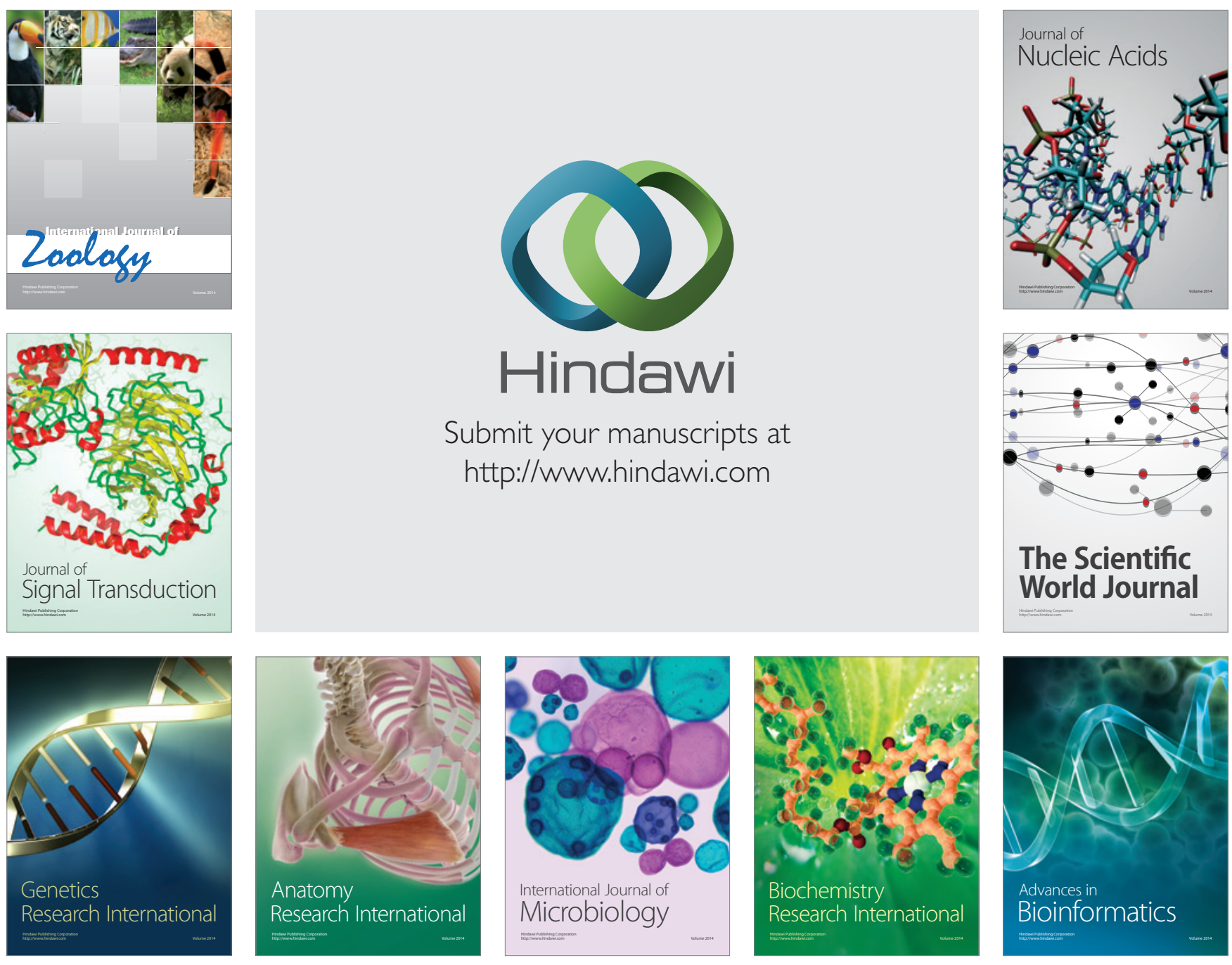

The Scientific World Journal
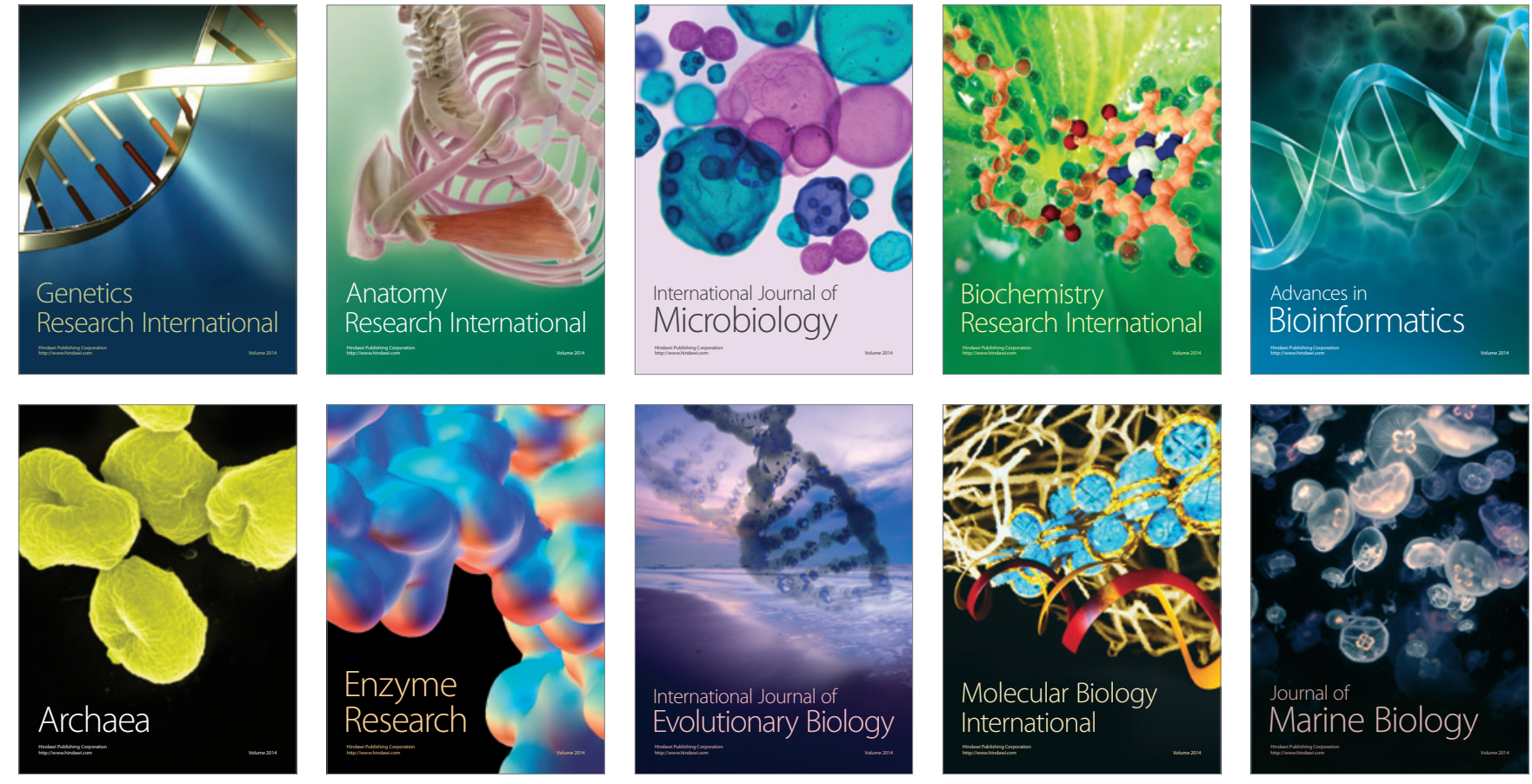